\title{
Gedunin Binds to Myeloid Differentiation Protein 2 and Impairs Lipopolysaccharide-Induced Toll-Like Receptor 4 Signaling in Macrophages $\$$
}

\author{
Perla Villani Borges, Katelim Hottz Moret, Clarissa Menezes Maya-Monteiro, Franklin \\ Souza-Silva, Carlos Roberto Alves, Paulo Ricardo Batista, Ernesto Raúl Caffarena, \\ Patrícia Pacheco, Maria das Graças Henriques, and Carmen Penido \\ Laboratory of Applied Pharmacology, Institute of Drug Technology (P.V.B., K.H.M., P.P., M.d.G.H., C.P.), Computational Science \\ Program, Computational Biophysics and Molecular Modeling Group (P.R.B.; E.R.C.), and Center for Technological Development \\ in Health (M.G.H., C.P.), Oswaldo Cruz Foundation, Rio de Janeiro, Brazil; and Laborator of Immunopharmacology (C.M.M.-M.) \\ and Molecular Biology and Endemic Diseases (F.S.S., C.R.A.), Oswaldo Cruz Institute, Oswaldo Cruz Foundation, Rio de Janeiro, \\ Brazil
}

Received March 13, 2015; accepted August 26, 2015

\begin{abstract}
Recognition of bacterial lipopolysaccharide (LPS) by innate immune system is mediated by the cluster of differentiation 14/ Toll-like receptor 4/myeloid differentiation protein 2 (MD-2) complex. In this study, we investigated the modulatory effect of gedunin, a limonoid from species of the Meliaceae family described as a heat shock protein Hsp90 inhibitor, on LPS-induced response in immortalized murine macrophages. The pretreatment of wild-type (WT) macrophages with gedunin $(0.01-100 \mu \mathrm{M}$, noncytotoxic concentrations) inhibited LPS (50 ng/ml)-induced calcium influx, tumor necrosis factor- $\alpha$, and nitric oxide production in a concentration-dependent manner. The selective effect of gedunin on MyD88-adapter-like/myeloid differentiation primary response 88- and TRIF-related adaptor molecule/TIR domain-containing adapter-inducing interferon- $\beta$-dependent signaling pathways was further investigated. The pretreatment of WT, TIR domain-containing adapter-inducing interferon- $\beta$ knockout, and MyD88 adapter-like knockout macrophages
\end{abstract}

with gedunin $(10 \mu \mathrm{M})$ significantly inhibited LPS $(50 \mathrm{ng} / \mathrm{ml})-$ induced tumor necrosis factor- $\alpha$ and interleukin- 6 production, at 6 hours and 24 hours, suggesting that gedunin modulates a common event between both signaling pathways. Furthermore, gedunin $(10 \mu \mathrm{M})$ inhibited LPS-induced prostaglandin $\mathrm{E}_{2}$ production, cyclooxygenase-2 expression, and nuclear factor $\kappa \mathrm{B}$ translocation into the nucleus of WT macrophages, demonstrating a wide-range effect of this chemical compound. In addition to the ability to inhibit LPS-induced proinflammatory mediators, gedunin also triggered anti-inflammatory factors interleukin-10, heme oxygenase-1, and Hsp70 in macrophages stimulated or not with LPS. In silico modeling studies revealed that gedunin efficiently docked into the MD-2 LPS binding site, a phenomenon further confirmed by surface plasmon resonance. Our results reveal that, in addition to Hsp90 modulation, gedunin acts as a competitive inhibitor of LPS, blocking the formation of the Toll-like receptor 4/MD-2/LPS complex.

\section{Introduction}

Recognition of lipopolysaccharide (LPS), the main component of the outer membrane of Gram-negative bacteria, by the immune system, involves at least three receptor molecules:

This research was supported by the Carlos Chagas Filho Foundation for Research Support of the State of Rio de Janeiro and by the National Council for Scientific and Technological Development. P.V.B. and K.H.M. were supported by fellowships from the Coordination for the Improvement of Higher Education Personnel Foundation and the National Council for Scientific and Technological Development as students of the Oswaldo Cruz Institute (Fiocruz) Graduate Program in Cellular and Molecular Biology.

P.V.B and K.H.M. are co-first authors of this work.

dx.doi.org/10.1124/mol.115.098970.

S This article has supplemental material available at molpharm. aspetjournals.org. cluster of differentiation 14 (CD14), Toll-like receptor (TLR) 4, and myeloid differentiation protein 2 (MD-2), which are mostly expressed by macrophages (Wright et al., 1990; Ulevitch and Tobias, 1995; Shimazu et al., 1999; Viriyakosol et al., 2000). LPS recognition by the TLR4 complex leads to the recruitment of the adaptor proteins MyD88-adapter-like/ Myeloid differentiation primary response 88 (MAL/MyD88) and TRIF-related adaptor molecule/TIR domain-containing adapter-inducing interferon- $\beta$ (TRAM/TRIF), which in turn activate two distinct signaling pathways that present different kinetics. TLR4 initially recruits MAL/MyD88, leading to early phase activation, and is further endocytosed and delivered to intracellular vesicles to only then form a complex

ABBREVIATIONS: 17-AAG, 17-allylamino-17-demethoxy-geldanamycin; CD14, cluster of differentiation 14; COX-2, cyclooxygenase-2; DMEM, Dulbecco's modified Eagle's medium; FBS, fetal bovine serum; HO-1, heme oxygenase-1; HSF-1, heat shock factor-1; IL, interleukin; LPS, lipopolysaccharide; MAL KO, MyD88 adapter-like knockout; MAPK, mitogen-activated protein kinase; NF $\kappa$, nuclear factor $\kappa \mathrm{B}$; NO, nitric oxide; $\mathrm{PGE}_{2}$, prostaglandin $\mathrm{E}_{2}$; RU, resonance unit; SPR, surface plasmon resonance; TLR, Toll-like receptor; TNF, tumor necrosis factor; TRIF KO, TIR domain-containing adapter-inducing interferon- $\beta$ knockout; WT, wild type. 
with TRAM/TRIF, leading to the late phase activation (Hwang et al., 1997; Kagan et al., 2008; Kawai and Akira, 2011). These two pathways are required to drive robust nuclear factor $\kappa \mathrm{B}$ $(\mathrm{NF} \kappa \mathrm{B})$ and mitogen-activated protein kinase (MAPK) activation and the subsequent induction of inflammatory cytokines such as tumor necrosis factor (TNF)- $\alpha$, interleukin (IL)-6, IL$1 \beta$, and nitric oxide (NO) (Byrd-Leifer et al., 2001; Fitzgerald et al., 2003; Sato et al., 2003; Li et al., 2005a; Gais et al., 2010). The overproduction of these mediators during inflammation can lead to tissue damage, multiple organ dysfunction, and septic shock (Dos Santos and Slutsky, 2000; Marshall, 2001; $\mathrm{Su}, 2002$; Shen et al., 2004).

It has been proposed that the heat shock protein (Hsp) chaperone machinery is implicated in TLR4/MD-2/CD14 signaling by maintaining the structural integrity of the multimeric LPS receptor complex and by regulating MAPK members (Triantafilou et al., 2001; Echeverría et al., 2011). In addition, it has been suggested that LPS is transferred from CD14 to Hsp70 and Hsp90, and then interacts with a large hydrophobic pocket of MD-2 (da Silva Correia et al., 2001; Triantafilou et al., 2001; Park et al., 2009). Hsp90 is an abundantly and ubiquitously expressed chaperone that helps to maintain, at the expense of ATP, the structure of several membrane, cytoplasmic, and endoplasmic reticulumassociated client proteins (Pratt and Toft, 1997; Picard, 2002; Zhao and Houry, 2005; McClellan et al., 2007). Hsp90 chaperoning activity can be inhibited by geldanamycin, 17allylamino-17-demethoxy-geldanamycin (17-AAG), and celastrol, which leads to increased degradation of Hsp90 client proteins (Matts et al., 2011). In experimental models, Hsp90 inhibitors have been shown to suppress different signaling pathways and display potent antiproliferative, cytoprotective, and anti-inflammatory activities (Lewis et al., 2000; Poulaki et al., 2007; Ambade et al., 2012; Chow et al., 2013; Leung et al., 2015). These effects result from nonfunctional conformational changes as well as from the induction of heat shock response via the activation of heat shock factor-1 (HSF-1), which leads to increased expression of Hsp90 and other Hsps, including Hsp70, Hsp40, and Hsp32 [heme oxygenase-1 (HO-1)] (Pritchard et al., 2001; Shamovsky and Nudler, 2008; Trott et al., 2008; Chow et al., 2013).

Gedunin and its analogs are an important bioactive limonoid-type tetranortriterpene isolated from the Meliaceae family and are reported to display a wide range of biologic activities, including antitumor, antimalarial, antiallergic, and anti-inflammatory activity in different experimental models (Brandt et al., 2008; Kamath et al., 2009; Ferraris et al., 2011, 2012; Miranda Júnior et al., 2012; Henriques and Penido, 2014; Conte et al., 2015). The molecular mechanism of action related to the biologic effects of gedunin relies on the inhibition of Hsp90 activity via specific binding to the cochaperone p23 and by disrupting the cochaperone Cdc37-Hsp90 interaction (Matts et al., 2011; Patwardhan et al., 2013). However, here we demonstrate that gedunin mechanisms of action go beyond Hsp90 modulation. Using in silico and surface plasmon resonance (SPR) analysis, we show that gedunin binds to MD-2, impairing TLR4/MD-2/CD14 signaling and decreasing LPS-induced inflammatory response in murine macrophages.

\section{Materials and Methods}

Cell Culture. Immortalized bone marrow-derived macrophage cell lines generated from wild-type (WT), MyD88 adapter-like knockout (MAL KO), and TIR domain-containing adapter-inducing interferon- $\beta$ (TRIF KO) C57BL/6 mice (a kind gift from Douglas Golenbock, University of Massachusetts Medical School, Worcester, MA) were cultured in Dulbecco's modified Eagle's medium (DMEM) (Sigma-Aldrich, St. Louis, MO) supplemented with fetal bovine serum (FBS) (10\%; Gibco/Life Technologies, Carlsbad, CA), sodium pyruvate (1 mM, Sigma-Aldrich), and ciprofloxacin (10 $\mu \mathrm{g} / \mathrm{ml}$, Fresoflox; Fresenius Kabi, Barueri, Brazil).

Cytotoxicity Assay. To perform in vitro assays with gedunin, we first examined the cytotoxic effects of this substance (and gedunin vehicle, dimethylsulfoxide) on WT immortalized macrophages. Viable cells were seeded in a flat bottom 96 -well plate $\left(2 \times 10^{5}\right.$ cells/well, in quadruplicate) and cultured for 24 hours in the presence of different concentrations of gedunin $\left(0.001-1000 \mu \mathrm{M} ; 5 \% \mathrm{CO}_{2}\right.$ at $\left.37^{\circ} \mathrm{C}\right)$. The assay was assessed by the resazurin reduction method. The absorbance was read at $555 / 585 \mathrm{~nm}\left(\lambda_{\text {ex }} / \lambda_{\text {em }}\right)$ using a Spectramax M5 microplate reader (Molecular Devices, Sunnyvale, CA) and results are expressed as percentages of viable cells (Table 1). The compound concentrations that induced $\geq 10 \%$ of cell death were considered cytotoxic and were not used in the biologic assays. It is noteworthy that dimethylsulfoxide ( $\leq 0.1 \%$, maximal concentration used) and LPS $(\leq 1 \mu \mathrm{g} / \mathrm{ml})$ induced $\leq 10 \%$ of macrophage death.

Treatments and Stimulation. WT, MAL KO, and TRIF KO macrophages $\left(10^{6}\right.$ cells/well $)$ were plated in 6 - or 24 -well plates in DMEM (supplemented with $2 \%$ FBS, $1 \mathrm{mM}$ sodium pyruvate, and $10 \mu \mathrm{g} / \mathrm{ml}$ ciprofloxacin) for 24 hours and then treated with gedunin (0.01-100 $\mu \mathrm{M}$; Gaya Chemical Corporation, New Milford, CT). After 1 hour, macrophages were stimulated with LPS $(50-1000 \mathrm{ng} / \mathrm{ml}$, from Escherichia coli O111:B4, Sigma-Aldrich) and repurified by a repeated phenolchloroform extraction (Hirschfeld et al., 2000) for 6 or 24 hours, and the cell-free supernatants were recovered for analysis. Hsp90 inhibitor 17-AAG $(1 \mu \mathrm{M})$ and dexamethasone (100 $\mathrm{nM})$, used as reference inhibitors, were purchased from Sigma-Aldrich and induced $\leq 10 \%$ of macrophage death at the concentrations used.

Calcium Mobilization Assay. Intracellular calcium concentrations on preplated WT immortalized macrophage cells $\left(2 \times 10^{5}\right.$ per well) were pretreated with gedunin $(0.01-100 \mu \mathrm{M})$ and exposed to LPS $(1 \mu \mathrm{g} / \mathrm{ml})$ over 600 seconds using the FLIPR Calcium Plus Assay Kit on a FlexStation II fluorometric microplate reader (Molecular Devices), with fluorescence intensity ratios at $485 / 525 \mathrm{~nm}\left(\lambda_{\text {ex }} / \lambda_{\text {em }}\right)$ recorded up to 5 minutes and analyzed using SoftMax Pro (Molecular Devices).

Nitrite Determination. Cells were seeded on 24 -well plates in a final concentration of $1 \times 10^{6}$ cells/well (DMEM supplemented with

TABLE 1

Macrophage viability after exposure to gedunin

Results are expressed as the percentage of cell viability from quadruplicate wells $\left(2 \times 10^{5}\right.$ cell/well), after incubation of macrophages with gedunin from 24 hours $\left(37^{\circ} \mathrm{C}, 5 \% \mathrm{CO}_{2}\right)$. Cell viability was assessed by the resazurin reduction method, as described in Materials and Methods.

\begin{tabular}{|c|c|c|c|c|c|c|c|c|}
\hline \multirow{2}{*}{ Medium } & \multirow{2}{*}{ Tween $20(3 \%)$} & \multicolumn{7}{|c|}{ Gedunin } \\
\hline & & 0.001 & 0.01 & 0.1 & 1 & 10 & 100 & 1000 \\
\hline & & & & & $\mu M$ & & & \\
\hline $100 \pm 2.90$ & $2.7 \pm 0.05$ & $100 \pm 1.23$ & $100 \pm 3.46$ & $100 \pm 0.22$ & $100 \pm 1.97$ & $100 \pm 4.74$ & $91.5 \pm 3.96$ & $86.9 \pm 0.39$ \\
\hline
\end{tabular}


$2 \% \mathrm{FBS}$, in $5 \% \mathrm{CO}_{2}$ at $37^{\circ} \mathrm{C}$ ) and allowed to grow to confluence. Confluent cells were pretreated with gedunin $(0.01-10 \mu \mathrm{M})$ and exposed to LPS (50 ng/ml) for 24 hours. The supernatant was collected and nitrite, a stable metabolite of NO in aqueous solutions, was measured by Griess reaction, after the addition of $100 \mu \mathrm{l}$ modified Griess reagent (Sigma-Aldrich) to the wells for 15 minutes at room temperature. Absorbance was read at $562 \mathrm{~nm}$ using a Spectramax M5 microplate reader (Molecular Devices). The concentration of nitrite was calculated from a sodium nitrite standard curve (range, 1.5-100 $\mu \mathrm{M}$ ).

Cytokine Analysis. TNF- $\alpha$, IL-6, and IL-10 levels were evaluated in the supernatants of stimulated immortalized macrophages by an enzyme-linked immunosorbent assay using matched antibody pairs (Quantikine; R\&D Systems, Minneapolis, MN), according to the manufacturer's instructions. Results are expressed as picograms per milliliter.

Prostaglandin $\mathbf{E}_{2}$ Quantification. Concentrations of prostaglandin $\mathrm{E}_{2}\left(\mathrm{PGE}_{2}\right)$ were measured in the supernatants of LPS $(50 \mathrm{ng} / \mathrm{ml})-$ stimulated macrophages pretreated or not with gedunin $(10 \mu \mathrm{M}), 17-\mathrm{AAG}(1 \mu \mathrm{M})$, or dexamethasone (100 nM) using an EIA kit (Cayman Chemical Company, Ann Arbor, MI), according to the manufacturer's instructions.

Western Blot Analysis. Total protein content in cytoplasmic and nuclear extracts was determined by the Bradford reagent (SigmaAldrich). Cell lysates were denatured in Laemmli's sample buffer (50 mM Tris-HCl, pH 6.8, 1\% SDS, 5\% 2-mercaptoethanol, 10\% glycerol, and $0.001 \%$ bromophenol blue) and heated at $95^{\circ} \mathrm{C}$ for 3 minutes. Aliquots containing $30 \mu \mathrm{g}$ protein were resuspended in SDSPAGE loading buffer, resolved on $12 \%$ SDS acrylamide gels, and transferred onto polyvinyl difluoride (PVDF) Hybond membranes (Amersham Biosciences, Buckinghamshire, UK). After blocking with $5 \%$ nonfat dry milk/Tris-buffered saline containing $0.1 \%$ Tween 20 for 2 hours at room temperature, the membranes were probed overnight at $4^{\circ} \mathrm{C}$ with specific primary antibodies followed by horseradish peroxidase-labeled secondary antibodies. Rabbit polyclonal antimouse HO-1 (1:5000) and horseradish peroxidase-labeled goat polyclonal anti-rabbit antibodies (1:2500) were obtained from Enzo Life Sciences (Farmingdale, NY). Mouse monoclonal anti-goat Hsp70 (1:5000), mouse monoclonal anti-goat COX-2 (1:5000) and mouse monoclonal anti-rabbit $\mathrm{NF}_{\kappa} \mathrm{B}$ p65 (1:5000) were obtained from Santa Cruz Biotechnologies (Santa Cruz, CA). PVDF sheets were incubated with streptavidin-conjugated horseradish peroxidase $(1: 10,000)$ for 1 hour and developed by an ECL-Plus reagent (Enhanced Chemiluminescence; Amersham Biosciences) and visualized on Hyperfilm (Amersham Biosciences). The bands were quantified by densitometry, using the ImageJ software program (National Institutes of Health, Bethesda, MD).

In Silico Docking Simulations. The structures of the human MD-2 and the cochaperone p23 were taken from the Protein Data Bank codes 2E56 (Ohto et al., 2007) and 1EJF (Weaver et al., 2000), respectively. Before the docking simulation, the protein structure was prepared adding hydrogens and the protonation of titrable residues were calculated with the PROPKA program ( $\mathrm{Li}$ et al., 2005b), inside the pdb2pqr program (Dolinsky et al., 2004, 2007), considering a $\mathrm{pH}$ of 7 .

All molecular docking calculations were performed using the Autodock Vina program (Trott and Olson, 2010), in a two-step approach: 1) the blind docking procedure and 2) the pocket search procedure. The blind docking procedure consisted of searching the entire protein surface to determine the potential binding pocket(s). This was achieved using the grid center as the center of each protein, using a grid size big enough to cover the entire protein surface. After finding the binding pockets, we centered the grid center within the discovered binding pocket and performed a more accurate search by the pocket search procedure, using the following parameters: energy_range, 10; num_modes, 20; and exhaustiveness, 800 .

Physicochemical Binding Assays of Gedunin toward MD-2. The SPR analysis was performed on carboxyl sensor chips coated with nickel-nitrilotriacetic acid (HisCap; ICx Nomadics Inc., Stillwater, $\mathrm{OK})$ previously treated with an activation solution $\left(500 \mu \mathrm{M} \mathrm{NiCl}_{2}\right)$ in a constant flow $(10 \mu \mathrm{l} / \mathrm{min})$ at $37^{\circ} \mathrm{C}$ for 10 minutes, for each binding assay cycle. Prior the binding assay, the recombinant human rhMD-2 fusion protein (R\&D Systems) was immobilized $(0.1750 \mu \mathrm{g} / \mathrm{ml}$, flow rate of $5 \mu \mathrm{l} / \mathrm{min}$, for 10 minutes $)$ on the chip surface with reaction buffer (150 mM NaCl, $100 \mathrm{mM}$ HEPES, $\mathrm{pH}$ 7.4). It is important to note that due to the lack of a commercially available recombinant murine MD-2, rhMD-2 was used in this study. rhMD-2 shares $56 \%$ of identity with recombinant murine MD-2 at the amino acid level, and their common residues are essential for TLR4 activation by LPS (Zimmer et al., 2008; Park et al., 2009). The differences in surface charge distribution (electrostatic potential) of human and murine MD-2 binding pockets do not alter the hydrophobic interaction between LPS and MD-2 inside the cavity. The binding of gedunin and of LPS to immobilized MD-2 was performed using different concentrations in reaction buffer (gedunin: 0.001-1000 $\mu \mathrm{M}$ and 0.482-482.0 $\mu \mathrm{g} / \mathrm{ml}$; LPS: 0.482-482.0 $\mu \mathrm{g} / \mathrm{ml}$ ). At the end of each interaction step, the HisCap chip was treated with regenerating buffer $(0.7 \mathrm{M}$ imidazole, $\mathrm{pH} 8.0)$ at $37^{\circ} \mathrm{C}$ for 3 minutes ( $50 \mu \mathrm{l} / \mathrm{min}$ ). All binding assays were registered in real time using a sensorgram, and changes in the SPR angle ( $\theta$ spr) were expressed as arbitrary resonance units (RU). To avoid artifacts, RU values from the reference channel were subtracted from the RU values of test samples. All SPR analyses were performed in a SensíQ Pioneer optical transduction biosensor (ICx Nomadics Inc.).

The association and dissociation rates of complex formation were calculated based on the analysis of sensorgram graphs. Kinetic values were obtained using Qdat software (ICx Nomadics Inc.). Data for the affinity constant $\left(K_{\text {eq }}\right)$ and of Gibbs free energy $\left(\theta \mathrm{G}^{\circ}\right)$ for the complexes formed were derived from the $K_{\mathrm{a}}$ and $K_{\mathrm{d}}$ data (Souza-Silva et al., 2014). The reliability of the data was confirmed by double-reciprocal plots (1/response versus $1 /$ free analyte), as previously described (Pastushok et al., 2005; Samoylov et al., 2005). Inhibitory modes of gedunin for LPS $(9.64 \mu \mathrm{g} / \mathrm{ml})$ binding to immobilized MD-2 was performed using different concentrations of gedunin (0.482-482.0 $\mu \mathrm{g} / \mathrm{ml})$ in reaction buffer. The binding of gedunin $(14.5 \mu \mathrm{g} / \mathrm{ml})$ to MD-2 in the presence of LPS $(0.482-482.0 \mu \mathrm{g} / \mathrm{ml})$ was also compared.

Statistical Analysis. Data are reported as the mean \pm S.E.M. and were analyzed by means of analysis of variance, followed by the Student-Newman-Keuls test. Values of $P<0.05$ were regarded as significant.

\section{Results}

Concentration Effect of Gedunin on LPS-Induced Macrophage Activation. The effect of different concentrations of gedunin was evaluated in vitro on LPS-induced calcium influx and on TNF- $\alpha$ and nitrite production by WT macrophages. As observed in Fig. 1, A and B, the stimulation of macrophages with LPS $(1 \mu \mathrm{g} / \mathrm{ml})$ induced a sustained increased in the levels of intracellular calcium, which was inhibited by the pretreatment with gedunin, from 0.01 to $100 \mu \mathrm{M}$. Gedunin pretreatment also impaired LPS ( $50 \mathrm{ng} / \mathrm{ml}$ )induced TNF- $\alpha$ production by macrophages, in a concentrationdependent manner $\left(R^{2}=0.96 ; P<0.001\right.$; Fig. $\left.1 \mathrm{C}\right)$. In addition, as shown in Fig. 1D, LPS (50 ng/ml) plus interferon- $\gamma$ $(200 \mathrm{IU} / \mathrm{ml})$ increased nitrite production by macrophages, which was also inhibited by gedunin pretreatment from 0.01 to $10 \mu \mathrm{M}$. Since $10 \mu \mathrm{M}$ gedunin resulted in $100 \%$ viability (Table 1) and significantly impaired different parameters of macrophage activation, this concentration was used in all subsequent experiments.

Gedunin Impairs LPS-Induced Cytokine Production of Early and Late Phase Responses. LPS recognition by 
A

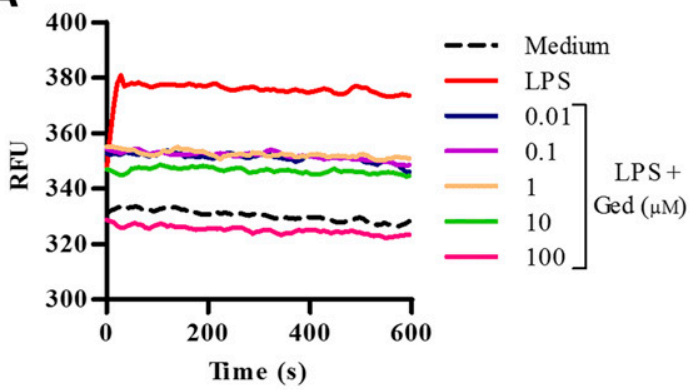

C

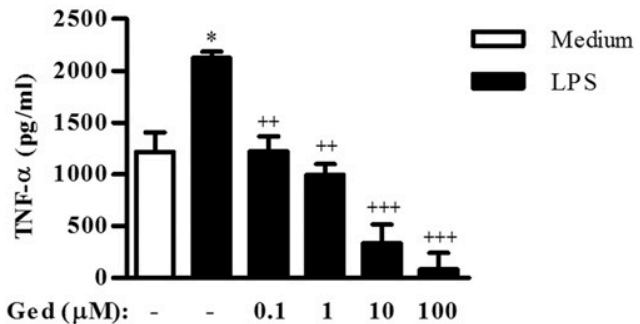

B

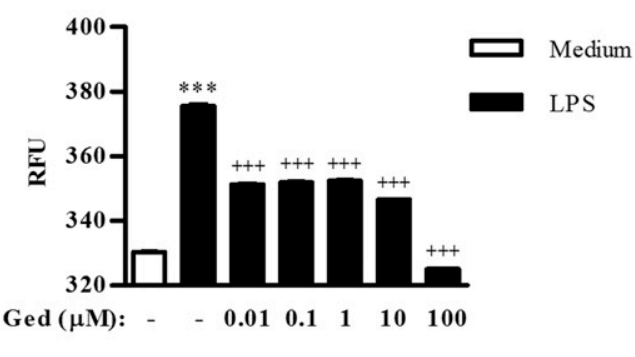

D

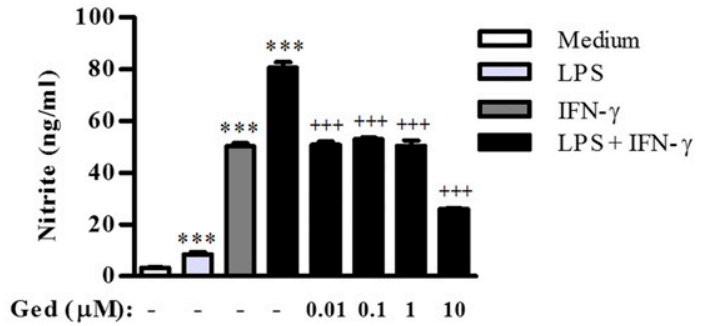

Fig. 1. Concentration-dependent inhibition of LPS-induced macrophage activation. In vitro pretreatment of WT immortalized macrophages (10 ${ }^{6}$ cells/ well) with gedunin (Ged; 0.1-100 $\mu \mathrm{M}$ ) for 1 hour impaired intracellular calcium influx (A and B), TNF- $\alpha$ (C), and NO production (D) by macrophages stimulated with LPS. (A) Kinetics of calcium influx of LPS (1 $\mu \mathrm{g} / \mathrm{ml})$-stimulated macrophages over 600 seconds measured by the FLIPR Calcium Plus Assay Kit and (B) means of values obtained within 600 seconds for each group. (C) TNF- $\alpha$ levels were determined by an enzyme-linked immunosorbent assay in the supernatants of macrophages 6 hours after LPS $(50 \mathrm{ng} / \mathrm{ml})$ stimulation. (D) NO was determined in supernatants of macrophages stimulated with LPS ( $50 \mathrm{ng} / \mathrm{ml}$ ) plus interferon (IFN)- $\gamma(200 \mathrm{IU} / \mathrm{ml})$ at 24 hours by the colorimetric Griess reagent. (C and D) Results are expressed as the mean \pm S.E.M. for triplicate wells per group from three independent experiments and were statistically analyzed by means of analysis of variance, followed by the Student-Newman-Keuls test. Statistically significant differences between stimulated and nonstimulated groups are indicated by asterisks $(* P<0.05$; $\left.{ }_{* * *} P<0.001\right)$, whereas plus signs $\left({ }^{++} P<0.01 ;{ }^{+++} P<0.001\right)$ represent differences between treated and stimulated groups.

the TLR4/MD-2/CD14 complex induces a signaling cascade that culminates in the production of cytokines, such as TNF- $\alpha$ and IL-6, via early (MAL/MyD88-dependent) and late (TRAM/ TRIF-dependent) pathways (Akira and Takeda, 2004). To investigate the selective effect of gedunin on the early and late activation triggered by LPS, we evaluated the production of cytokines by TRIF KO and MAL KO macrophages 6 and 24 hours after stimulation, respectively. As shown in Fig. 2, A-D, $\mathrm{TNF}-\alpha$ production through early and late pathways was significantly inhibited by gedunin, as well as by the reference inhibitors 17-AAG and dexamethasone pretreatments. Similarly, as shown in Fig. 2, E-H, the pretreatment with gedunin, 17-AAG, and dexamethasone inhibited IL-6 production via early and late phases.

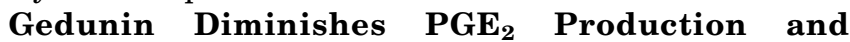
Cyclooxygenase-2 Expression Induced by LPS. We further evaluated the effect of gedunin on LPS-induced $\mathrm{PGE}_{2}$ production through early and late pathways. As shown in Fig. $3, \mathrm{~A}$ and $\mathrm{B}$, the pretreatment with gedunin, 17-AAG, and dexamethasone inhibited LPS-induced $\mathrm{PGE}_{2}$ production by WT macrophages 6 and 24 hours after stimulation. The expression of cyclooxygenase-2 (COX-2), the enzyme responsible for the production of prostanoids including $\mathrm{PGE}_{2}$ (Alhouayek and Muccioli, 2014), is shown to be induced after stimulation with LPS (Hwang et al., 1997; Rhee and Hwang, 2000) and IL-1 $\beta$ (Arias-Negrete et al., 1995; Endo et al., 2014). Here, we show that the pretreatment with gedunin decreased LPS (50 ng/ml)-induced COX-2 protein expression in WT immortalized macrophages (Fig. 3C). Decreased COX-2 expression was also observed for 17-AAG and dexamethasone.
Gedunin Inhibits Nuclear Translocation of NF $\kappa \mathrm{B} . \mathrm{NF}_{\kappa} \mathrm{B}$ activation is critical for the synthesis of inflammatory mediators, including cytokines (D'Acquisto et al., 2002). Thus, we investigated the ability of gedunin to inhibit $\mathrm{NF}_{\kappa} \mathrm{B}$ activation in vitro by analyzing its translocation into the nucleus by Western blot analysis. $\mathrm{NF}_{\kappa} \mathrm{B} / \mathrm{p} 65$ protein levels were determined in nuclear extracts of WT immortalized macrophages stimulated with LPS ( $50 \mathrm{ng} / \mathrm{ml}$ ) for 24 hours. LPS stimulation enhanced the presence of the p65 subunit in the nucleus, compared with nonstimulated WT immortalized macrophages (Fig. 3D). $\mathrm{NF} \kappa \mathrm{B}$ translocation was inhibited by gedunin, 17-AAG, and dexamethasone pretreatments.

Gedunin Triggers Anti-Inflammatory Mechanisms in Macrophages. The induction of anti-inflammatory and proresolving mechanisms may be an additional means by which anti-inflammatory substances exert their effects. Moreover, it has been demonstrated that some Hsp90 modulators can induce the expression of anti-inflammatory factors (Shamovsky and Nudler, 2008; Trott et al., 2008; Chow et al., 2013; Der Sarkissian et al., 2014). Here we show that gedunin pretreatment enhanced HO-1 expression on LPS (50 ng/ml)stimulated WT immortalized macrophages, whereas 17-AAG and dexamethasone pretreatment did not enhance the expression of HO-1 (Fig. 4A). The fact that LPS failed to increase HO-1 expression 6 hours after stimulation is in accordance with previous reports (Song et al., 2003; Rushworth et al., 2005). Incubation of unstimulated macrophages with gedunin induced more prominent expression of HO-1 compared with cells incubated with gedunin and LPS $(P \leq 0.05)$. In addition, gedunin and 17-AAG pretreatments were able to induce Hsp70 expression on WT immortalized macrophages that 


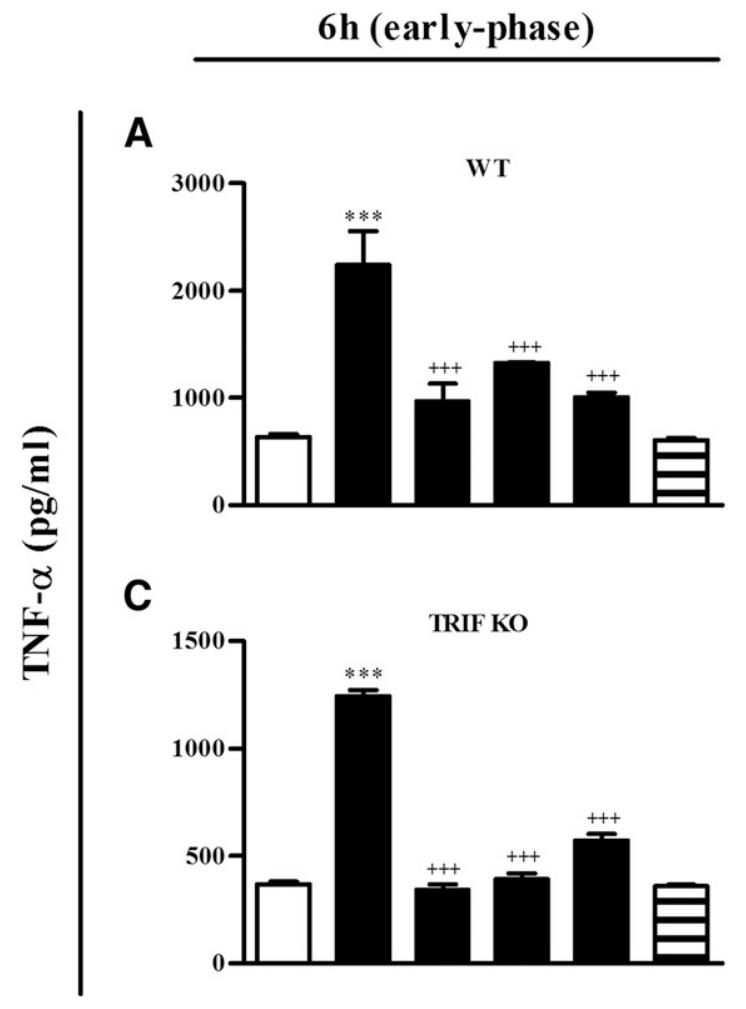

B

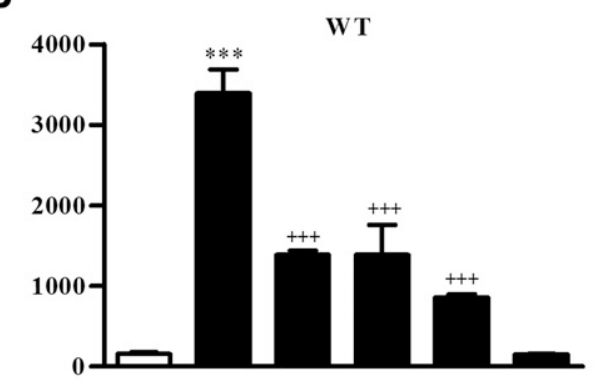

D
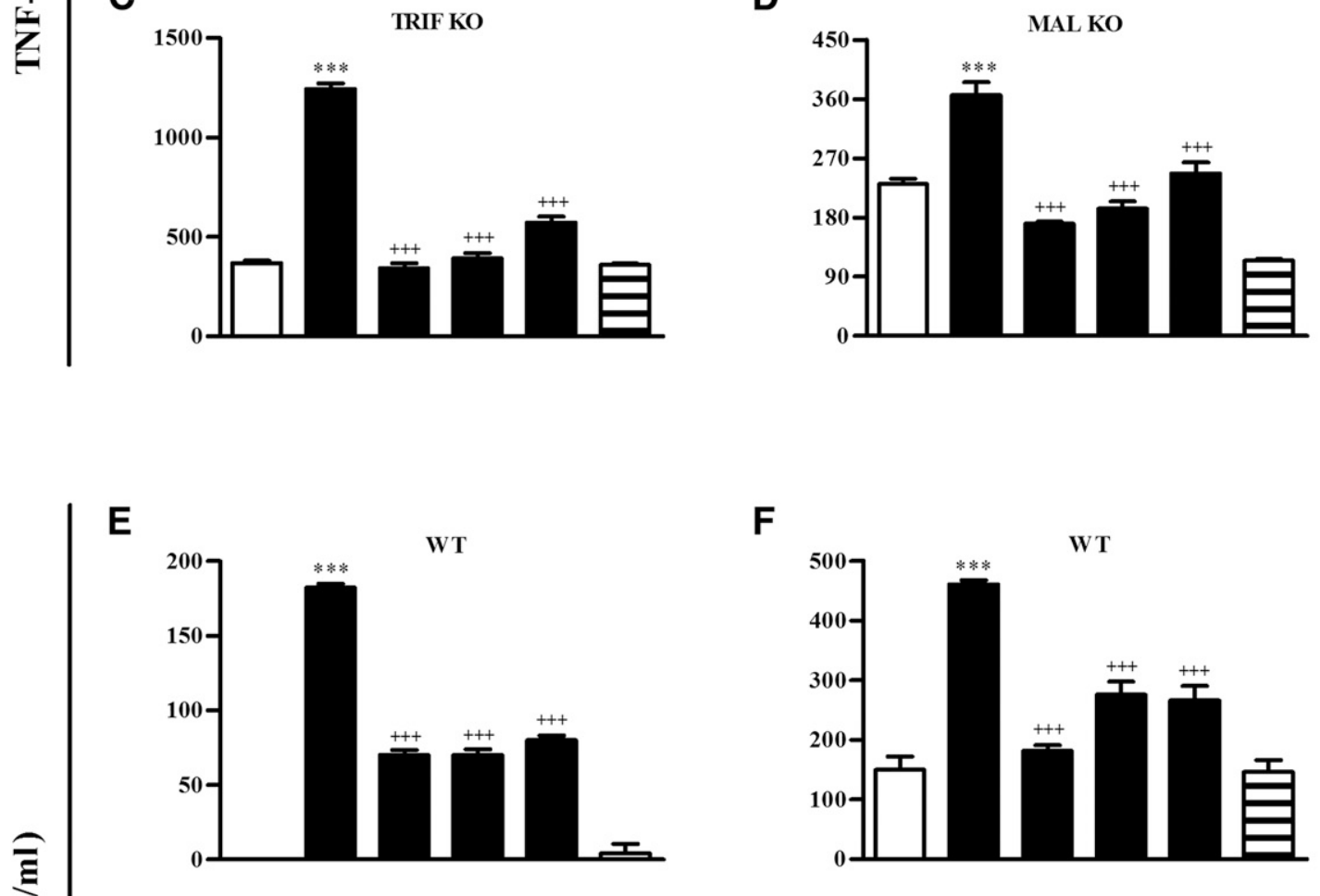

$\mathbf{F}$

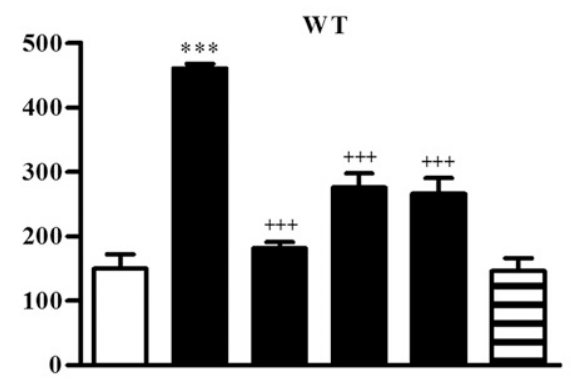

G

TRIF KO

H
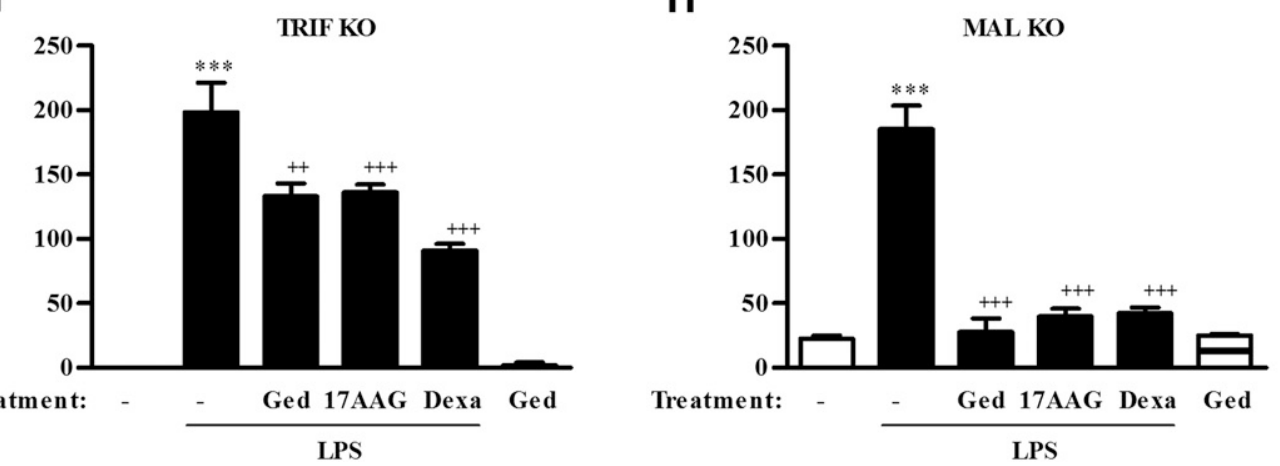

Fig. 2. Gedunin impairs LPS-induced cytokine production during early and late phase activation. Pretreatment of WT (A, B, E, and F), TRIF KO (C and G), and MAL KO (D and H) macrophages (106 cells/well) with gedunin (Ged; $10 \mu \mathrm{M})$, 17-AAG (1 $\mu \mathrm{M})$, or dexamethasone (Dexa; $100 \mathrm{nM})$ for 1 hour impaired LPS (50 ng/ml)-induced TNF- $\alpha$ (A-D) and IL-6 (E-H) at 6 hours (left-column graphs) and 24 hours (right-column graphs), as determined by an enzyme-linked immunosorbent assay in cell-free supernatants. Results are expressed as the mean \pm S.E.M. for quadruplicate wells per group from three independent experiments and were statistically analyzed by means of analysis of variance, followed by the Student-Newman-Keuls test. Statistically significant differences between stimulated and nonstimulated groups are indicated by asterisks $(* * * P<0.001)$, whereas plus signs $\left({ }^{++} P<0.01 ;{ }^{+++} P<\right.$ 0.001) represent differences between treated and stimulated groups. 
A

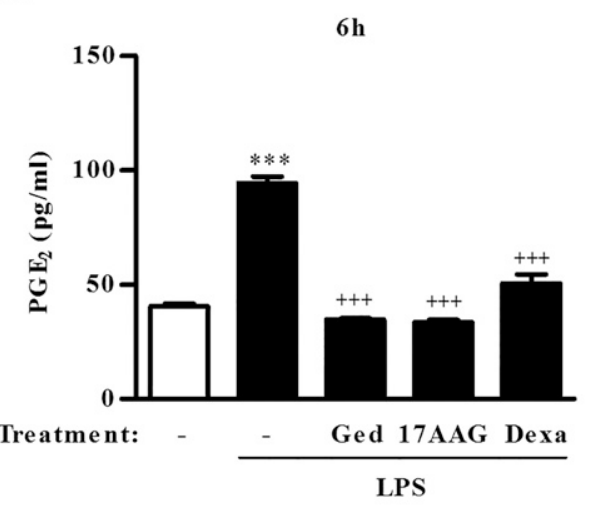

C
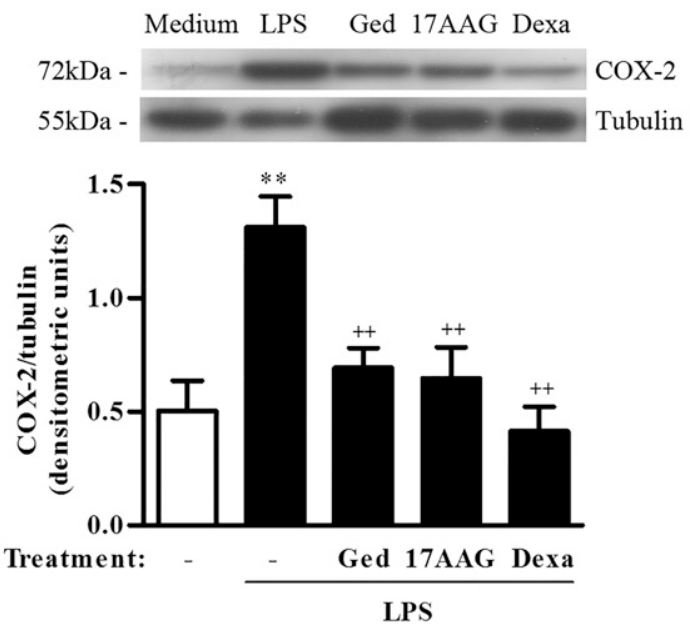

B

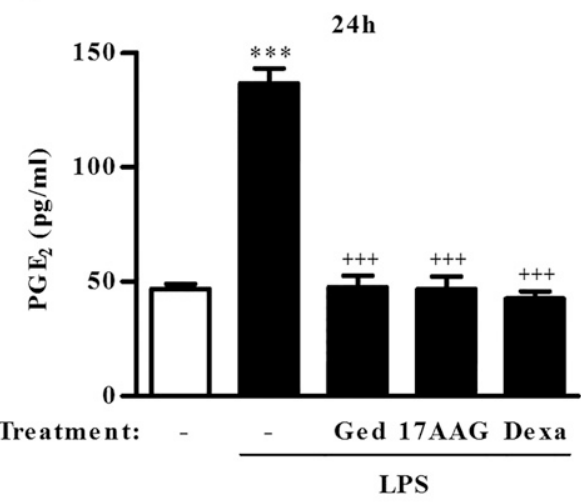

D

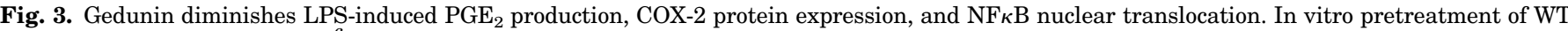

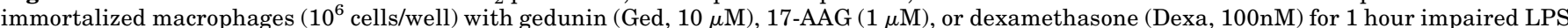

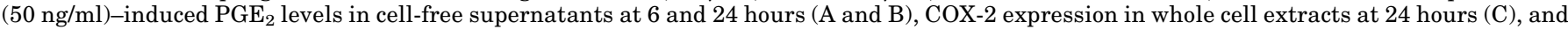

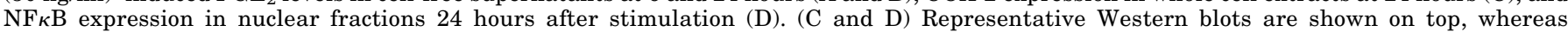

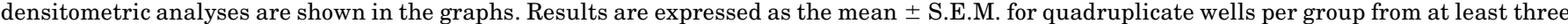

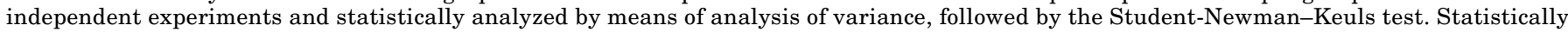

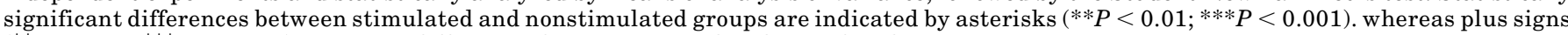
$\left.{ }^{++} P<0.01 ;{ }^{++} P<0.001\right)$ represent differences between treated and stimulated groups.

were stimulated with LPS (Fig. 4B). Similarly, the increase in Hsp70 expression observed in macrophages that were pretreated with dexamethasone was not statistically significant compared with LPS-stimulated macrophages. Furthermore, LPS-induced IL-10 production was enhanced in WT immortalized macrophages by pretreatments with gedunin, 17-AAG, and dexamethasone (Fig. 4C). Interestingly, the incubation of unstimulated macrophages with gedunin was able to induce increased HO-1 and IL-10 expression. Thus, our results show that gedunin is also capable of inducing anti-inflammatory factors in macrophages.

Gedunin Docks to the MD-2 Protein Surface at the LPS Binding Site. The complexity of the TLR4 signaling pathway (e.g., numerous proteins acting at different levels) hinders the identification of molecular targets of gedunin. We first analyzed the structure and interaction of known targets of gedunin. It was recently demonstrated that gedunin is able to bind and inactivate p23, avoiding the formation of its complex with Hsp90 (Patwardhan et al., 2013). Structurally, p23 presents an antiparallel $\beta$-sandwich fold and the gedunin binding site is located within the region that forms the complex to Hsp90. Using a binding docking scheme, we were able to find the same previously reported binding site that allowed us to obtain an equivalent binding mode of gedunin to p23 (Supplemental Fig. 1).

Among the potential candidates of proteins of the TLR4 pathway, we considered proteins that directly bind and recognize LPS, including the TLR4 accessory protein MD-2 (Meng et al., 2010). Considering that gedunin is a very hydrophobic molecule, we tested whether it would bind to MD-2.

Comparison between the sequences and crystal structures of MD-2 and p23 revealed that these two proteins possess a similar fold, as represented by the structural alignments of their crystal structures (Fig. 5). Thus, both MD-2 and p23 present an antiparallel $\beta$-sandwich fold with a well defined hydrophobic pocket (p23 being more compact).

Mapping Gedunin Binding Sites in MD-2. We then used an in silico docking approach to identify putative gedunin binding sites in the MD-2 structure. Our hypothesis is based 
A
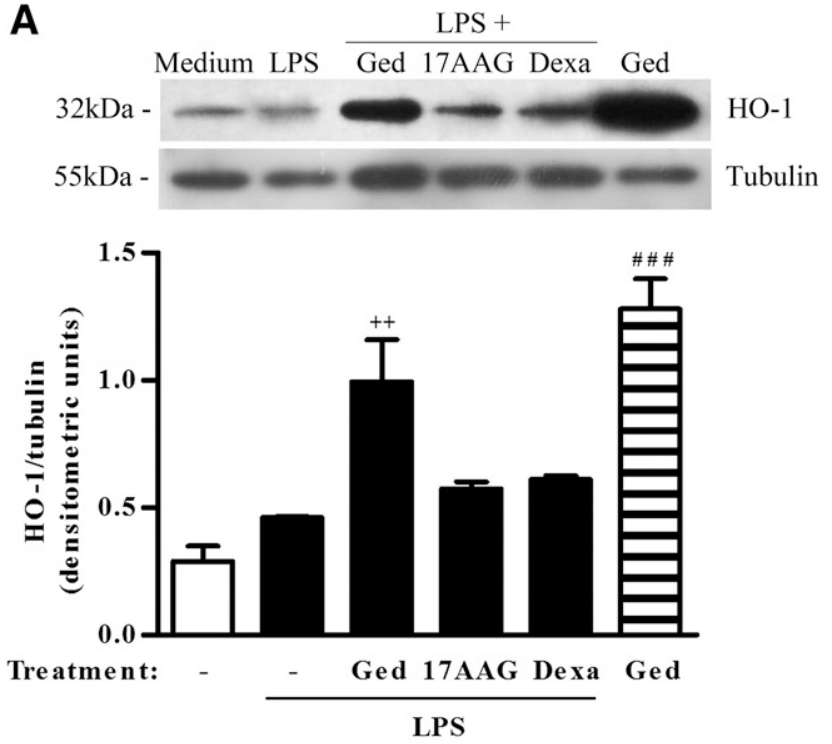

B
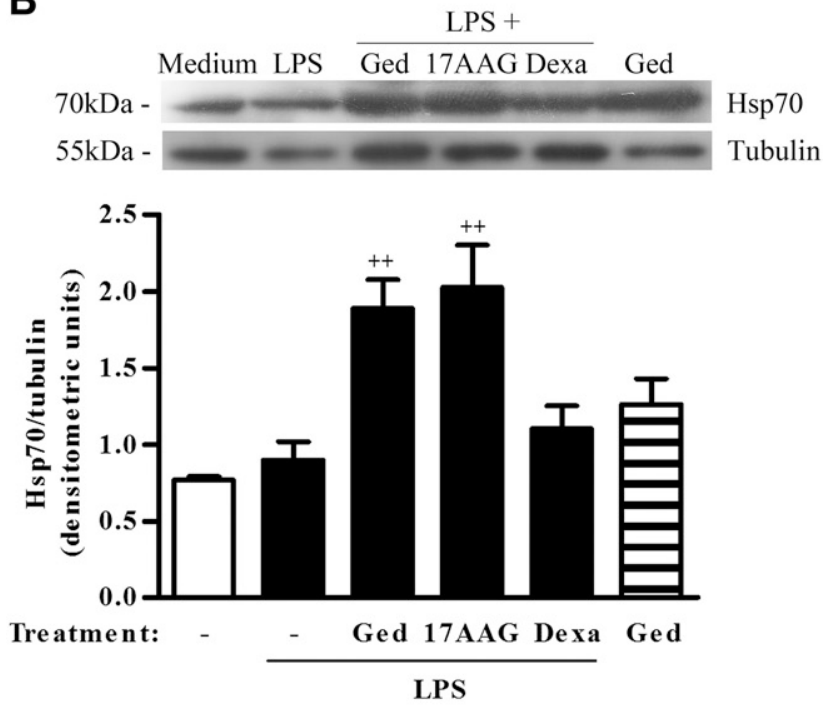

C

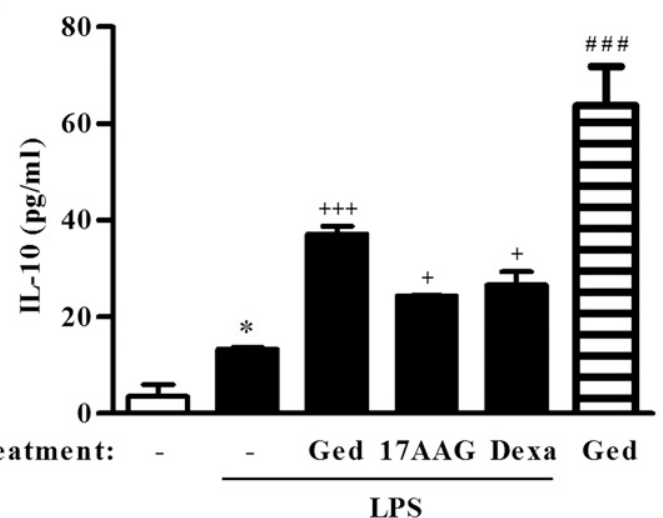

Fig. 4. Gedunin triggers anti-inflammatory mechanisms in macrophages. Expression of HO-1 (A) and Hsp70 (B) in whole WT immortalized macrophage extracts ( $10^{6}$ cells/well), 6 and 24 hours after LPS $(50 \mathrm{ng} / \mathrm{ml})$ stimulation, respectively, evaluated by Western blot analysis. Cell were pretreated for 1 hour with gedunin (Ged; $10 \mu \mathrm{M})$, 17-AAG $(1 \mu \mathrm{M})$, or dexamethasone (Dexa; $100 \mathrm{nM}$ ) before stimulation. Representative Western blots from three independent experiments are shown (top panels). (C) Effect of gedunin pretreatment on LPS $(50 \mathrm{ng} / \mathrm{ml})$-induced IL-10 production on two assumptions: 1) p23 and MD-2 share some structural similarity; and 2) since gedunin binds to p23, it probably binds to MD-2.

Our results show that gedunin docked to the large hydrophobic site that overlaps to the LPS binding site (Fig. 6). As illustrated in Fig. 6A, all 16 high-score poses were docked at the most hydrophobic region of the MD-2 protein surface, within the LPS binding pocket (the hydrophobic pocket). Moreover, the MD-2 residues interacting with the higherscore docked conformation of gedunin are all hydrophobic, including Val24, Ile32, Ile46, Val48, Ile52, Leu61, Leu78, Phe119, Phe121, Cys133, Val135, Phe151, and Ile153 (with the exception of the polar Ser120) (Fig. 6, B and C). Thus, according to our predictions, the binding of gedunin to the MD-2 surface would impair LPS binding, avoiding the formation of the complex between MD-2 and LPS.

Physicochemical Binding Assays to MD-2 Protein. The biosensor analysis performed here was useful to prove the binding property of MD-2 with its ligand, gedunin. The kinetics of the interaction was evaluated after activation of the HisCap sensor chip upon immobilization of the complexes, which was activated to recognize and bind to the histidine region of the MD-2. The binding of MD-2 protein to the HisCap chip exhibited a significant binding rate of $452 \pm 18 \mathrm{RU} / \mathrm{s}$ for the interaction with nickel-nitrilotriacetic acid. Therefore, the binding site of MD-2 was accessible to interact with gedunin in solution. The time RU/s variation in 890 seconds was used to evaluate the interactions between MD-2 and gedunin (Fig. 7A).

The dissociation values of MD-2 binding (in $\mathrm{RU} / \mathrm{s}$ ) were $1.3 \pm 0.1,1.6 \pm 0.2,3.4 \pm 0.4,4.0 \pm 0.2,5.7 \pm 0.6,13 \pm 0.1$, and $33.4 \pm 0.3$ for gedunin concentrations (in $\mu \mathrm{M}$ ) of $0.001,0.01$, $0.10,1.0,10.0,100.0$, and 1000.0, respectively (Fig. 7, A and B). The kinetic values of gedunin interaction with MD-2 was assessed by the affinity constant, as $K_{\mathrm{d}} 280 \pm 29 \mu \mathrm{M}$. Gedunin was further analyzed using a series of concentrations, which demonstrated an increase in the SPR signal (in RU/s), indicating that this limonoid directly binds to immobilized MD-2 in a concentration-dependent fashion $\left(R^{2}=0.925\right.$; Fig. 7B). Double-reciprocal plot linearization shows that gedunin binding to MD-2 occurs in a concentration-dependent fashion (Fig. 7C). Figure 7D shows the dose-response curves of gedunin and LPS binding to $\mathrm{MD}-2$, demonstrating $\mathrm{RU}_{\max }$ values of $38.653\left(R^{2}=0.952\right)$ for gedunin and $69.953\left(R^{2}=\right.$ 0.9846 ) for LPS. The double-reciprocal plot was performed to calculate $50 \%$ of saturation of binding of gedunin and LPS to immobilized MD-2 and revealed values of $14.5 \mu \mathrm{g} / \mathrm{ml}$ and $9.64 \mu \mathrm{g} / \mathrm{ml}$, respectively. The addition of gedunin $(14.5 \mu \mathrm{g} / \mathrm{ml})$ to LPS previously added to immobilized MD-2 at different concentrations diminished RU values of LPS binding $\left(R^{2}=\right.$ 0.9883 ), evaluated 20 seconds after dissociation time (Fig. 7E). A similar binding inhibition curve was observed when

by WT macrophages, evaluated in 24-hour cell-free supernatants by an enzyme-linked immunosorbent assay. Results are represented as the mean \pm S.E.M. for at least triplicate samples per group from three independent experiments. Statistical analysis was performed by means of analysis of variance, followed by the Student-Newman-Keuls test. Statistically significant differences between treated and stimulated groups are indicated by plus signs $\left({ }^{+} P<0.05 ;{ }^{++} P<0.01\right)$, whereas pound signs ( $\left.{ }^{\# \# \# ~} P<0.001\right)$ represent differences between treated and nonstimulated groups and asterisks ( $* P<0.1$ ) represent differences between stimulated and non- stimulated groups. 
A
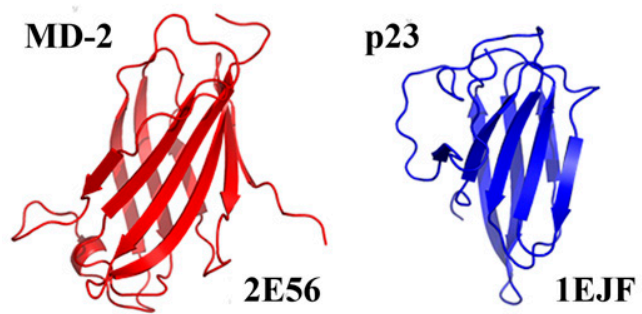

\section{Superimposition}

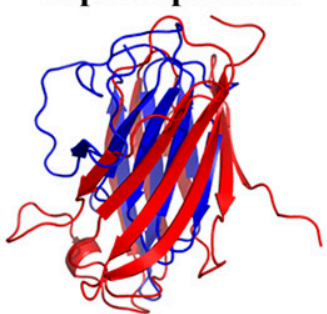

B

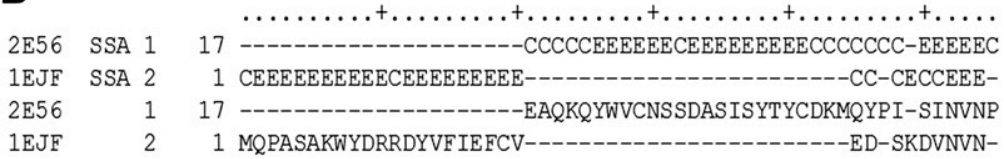

2 E56 SSA 1

1EJF SSA 2

2 E5 6

$1 \mathrm{EJF}$

2E56

$1 \mathrm{EJF}$

$2 \mathrm{E} 56$

$1 \mathrm{EJF}$

2E56 SSA 1

$1 \mathrm{EJF}$ SSA 2

2E56 1

$1 \mathrm{EJF} 2$ $\ldots \ldots \ldots \ldots+\ldots \ldots \ldots+\ldots \ldots \ldots+\ldots \ldots \ldots+\ldots \ldots \ldots+\ldots \ldots$ 51 CCCCCCEEEEEEEEECCCCCCCCEEEEEEEEEECEEECCEEEEECCCCCCCCCCCC 31 -EE-CEEE-EEEEEE-C-

51 CIELKGSKGLLHIFYIPRRDLKQLYFNLYITVNTMNLPKRKEVICRGSDDDYSFCR 31 -FE-KSKL-TFSCLG-G---------------------------------
Fig. 5. Structural alignment of the crystal structures of the human MD-2 and the cochaperone p23. (A) Representation of human MD-2 (Protein Data Bank identifier 2E56) in red on the left, p23 (Protein Data Bank identifier 1EJF) in blue in the middle, and the superposition of both structures on the right. (B) Secondary structure-based alignment of the sequences from MD-2 and p23 structures using the Protein Structure Alignment module of Maestro software (Suite 2012; Schrödinger LLC, New York, NY).

Alignment Score: 0.808

RMSD: 4.495 Angstrom

LPS $(9.64 \mu \mathrm{g} / \mathrm{ml})$ was added to gedunin at different concentrations ( $\left.R^{2}=0.8511\right)$, suggesting that gedunin might compete with LPS for the same binding region of MD-2. Figure 7F shows the percentage of inhibition calculated using the values demonstrated in Fig. 7E, considering $100 \%$ as the resonance signal of $1 / \mathrm{RU}_{\max }$ of gedunin $(\mathrm{RU}=19.33)$ and $\mathrm{LPS}(\mathrm{RU}=$ 35.00).

\section{Discussion}

In this study, we demonstrate that gedunin has a remarkable suppressive effect on macrophage activation induced by LPS. We also provide evidence that gedunin binds to the MD-2 component of the TLR4 complex and, by impairing the upstream activation of LPS signaling cascade, gedunin inhibits both early (MAL/MyD88-dependent) and late (TRAM/TRIFdependent) pathways.

Our group previously demonstrated that gedunin presents important anti-inflammatory and immunomodulatory effects in different experimental models in vivo, including experimental arthritis, allergic pleurisy, and allergic lung inflammation, in which macrophages play a pivotal role (Penido et al., 2005, 2006a,b; Henriques and Penido, 2014; Conte et al., 2015). Here, we demonstrate that gedunin directly modulates macrophages in vitro, in a concentration-dependent manner, inhibiting early and classic parameters of macrophage activation after pathogen-associated molecular pattern recognition. The fact that different pathways are involved in calcium influx and TNF- $\alpha$ and NO production reinforces that gedunin blocks an upstream and common mechanism involved in these three responses, most likely due to MD-2 binding. However, the modulation of Hsp90 by gedunin (Brandt et al., 2008; Patwardhan et al., 2013) also explains the impairment of LPSinduced NO production, since NO synthesis has been shown to be modulated by Hsp90, through Hsp90-inducible nitric oxide synthase interaction (Yoshida and Xia, 2003; Luo et al., 2011). Indeed, it was previously reported that Hsp90 inhibition by geldanamycin also impaired NO production by macrophages stimulated with LPS (Luo et al., 2011).

The recognition of LPS by the TLR4/MD-2/CD14 complex culminates in the production of TNF- $\alpha$ and IL- 6 via both MAL/MyD88- and TRAM/TRIF-dependent pathways (Wax et al., 2003; Akira and Takeda, 2004). Hsp90 (in association with Hsp70 and other chaperones) maintains the conformation and activity of MAL/MyD88- and TRAM/TRIF-dependent kinases involved in TNF- $\alpha$ and IL- 6 production, such as p38, extracellular signal-regulated kinase $1 / 2$, and c-Jun $\mathrm{N}$-terminal kinase (Davis and Carbott, 1999; Richter and Buchner, 2001; 
A

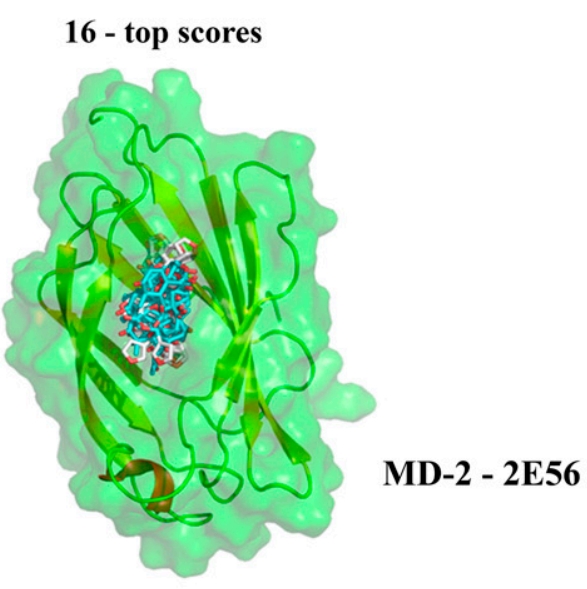

B

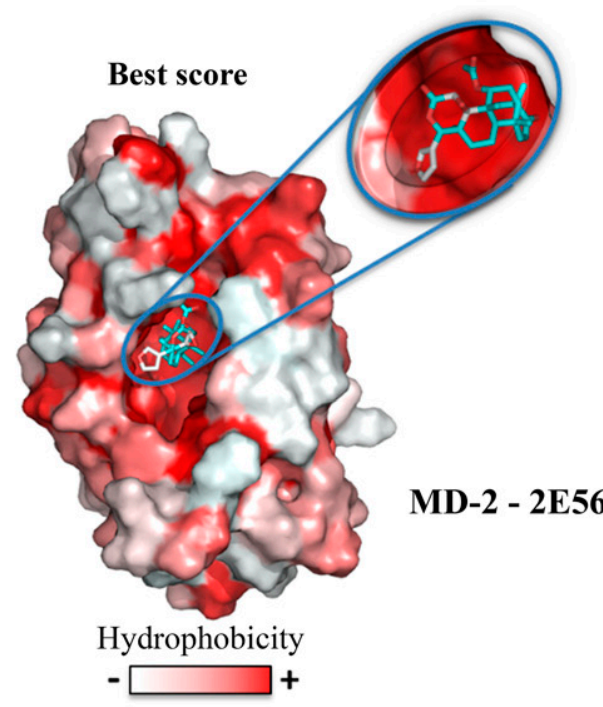

C

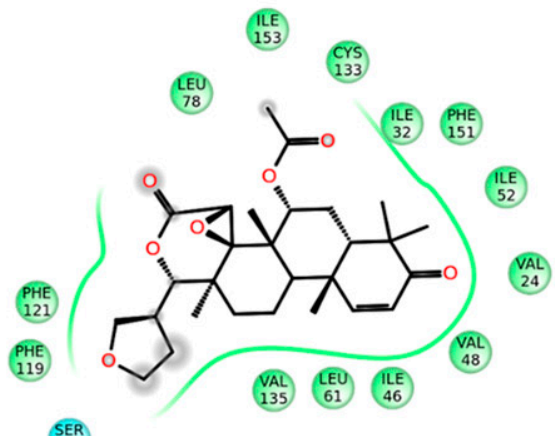

$\left.\begin{array}{l}\text { SER } \\ 120\end{array}\right)$

Solvent exposure

Polar

Hydrophobic

Fig. 6. In silico molecular docking reveals the binding mode of gedunin on the MD-2 structure (Protein Data Bank identifier 2E56). (A) The 16 top high-score conformations of gedunin within the hydrophobic pocket. Representation plus molecular surface of human MD-2. (B) Best-score predicted pose of gedunin on the molecular surface of MD-2, colored according to the Eisenberg normalized consensus hydrophobicity scale (Eisenberg et al., 1984). (C) Two-dimensional ligand interactions diagram of gedunin within the hydrophobic pocket, generated using Maestro
Beutler et al., 2003; Bode et al., 2003; Yamamoto et al., 2003; Echeverría et al., 2011). Indeed, geldanamycin has been shown to inhibit TNF- $\alpha$ and IL-6 mRNA as well as protein levels in LPS-stimulated macrophages (Vega and De Maio, 2003; Wax et al., 2003). Whether gedunin distinctly modulates MAL/ MyD88 and TRAM/TRIF pathways was investigated here by means of TRIF and MAL KO macrophages. The fact that this limonoid impaired cytokine production via both signaling cascades supports our assumption that gedunin acts upstream in LPS-induced macrophage activation. This effect is likely to occur either via MD-2 blockade (as revealed by our in silico and SPR experiments) or via modulation of TLR4-associated Hsp90, as previously proposed (Latz et al., 2002; Triantafilou and Triantafilou, 2004; Triantafilou et al., 2004, 2008). These authors have suggested, by means of fluorescence recovery after photobleaching analysis, that Hsp90 is part of the multimeric LPS receptor complex (Triantafilou et al., 2001). It is noteworthy that the ability of gedunin to modulate both MAL/ MyD88 and TRAM/TRIF pathways independently of TLR4/ MD-2 was also observed, since gedunin treatment impaired TNF- $\alpha$ production by macrophages stimulated with Pam3 (a TLR2 selective agonist) and polyinosinic/polycytidylic acid (a TLR3 selective agonist) (Supplemental Fig. 2). These data reinforce the role of Hsp90 in this phenomenon, since several kinases involved in MAL/MyD88 and TRAM/TRIF pathways are regulated by Hsp90 chaperoning activity (Yang et al., 2006; Hinz et al., 2007; Shi et al., 2009; Yun et al., 2011).

In addition to cytokines, LPS in vitro stimulation triggers increased COX-2 expression and $\mathrm{PGE}_{2}$ production by macrophages via the TRIF signaling pathway (Endo et al., 2014). In accordance, we demonstrate here that WT macrophages produced higher amounts of $\mathrm{PGE}_{2} 24$ hours, rather than 6 hours, after LPS stimulation, a time point in which the TRIF signaling pathway is most prominent. Nonetheless, gedunin pretreatment diminished $\mathrm{PGE}_{2}$ production to basal levels during early and late responses. As mentioned above, Hsp90 plays an important role in the regulation of MAPK family members and, by stabilizing transforming growth factor $\beta$-activated kinase 1 , triggers MAPKs and $\mathrm{NF} \kappa \mathrm{B}$ activation, involved in COX-2 expression (Eliopoulos et al., 2002; Shi et al., 2009; Echeverría et al., 2011; Bode et al., 2012). There are different mechanisms proposed for Hsp90 modulation of $\mathrm{NF}_{\kappa} \mathrm{B}$. It has been shown that geldanamycin reduces LPS-mediated $\mathrm{NF}_{\kappa} \mathrm{B}$ nuclear translocation in murine macrophages (Byrd et al., 1999). Malhotra et al. (2001) demonstrated that modulation of Hsp90 activity by geldanamycin did not impair inhibitor of $\kappa \mathrm{B}$ degradation or $\mathrm{NF}_{\kappa} \mathrm{B}$ translocation into the nucleus; however, it reduced the formation of the $\mathrm{NF}_{\kappa} \mathrm{B} / \mathrm{DNA}$ complex and, therefore, inhibited activation of cytokine promoter. Other reports have demonstrated that the inhibition of Hsp90 activity by geldanamycin reduced the stability of LPS-induced TNF- $\alpha$ and IL-6 transcripts, a phenomenon partially dependent of p38 (Wax et al., 2003). Our results demonstrate that, in our model, gedunin impaired LPSinduced $\mathrm{NF}_{\kappa} \mathrm{B}$ translocation in macrophages, reinforcing the additional role of this limonoid in modulating Hsp90 in

software (Suite 2012; Schrödinger LLC, New York, NY). Polar and hydrophobic amino acids are illustrated in blue and green circles. 
A

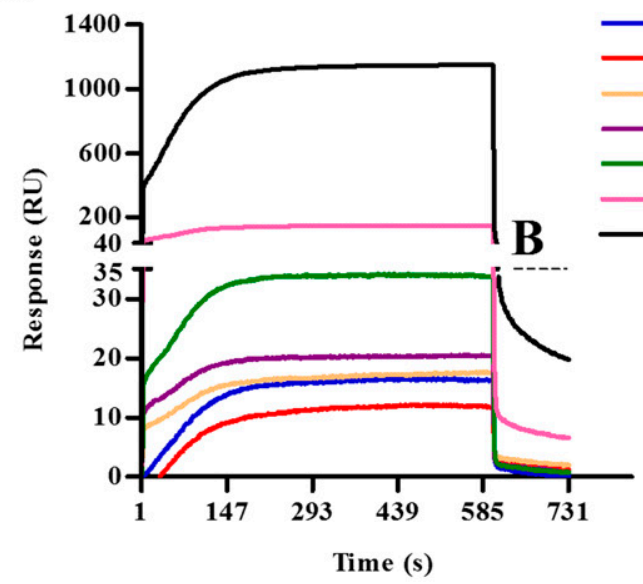

B

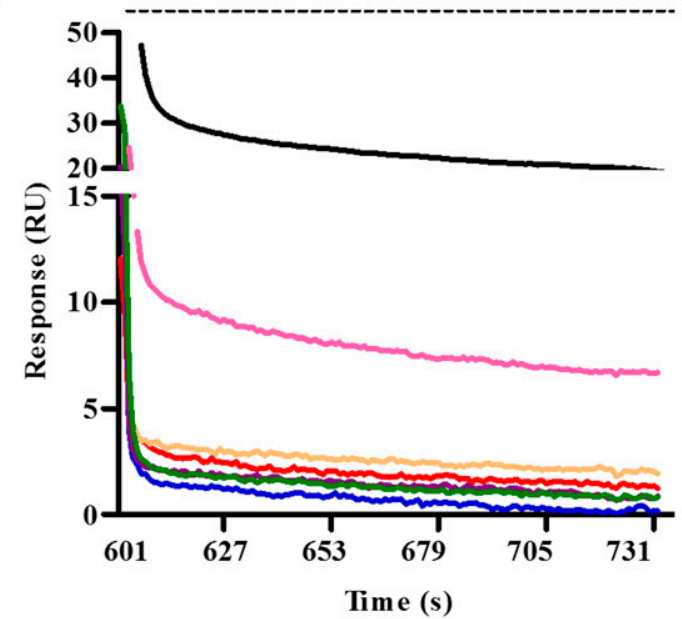

C

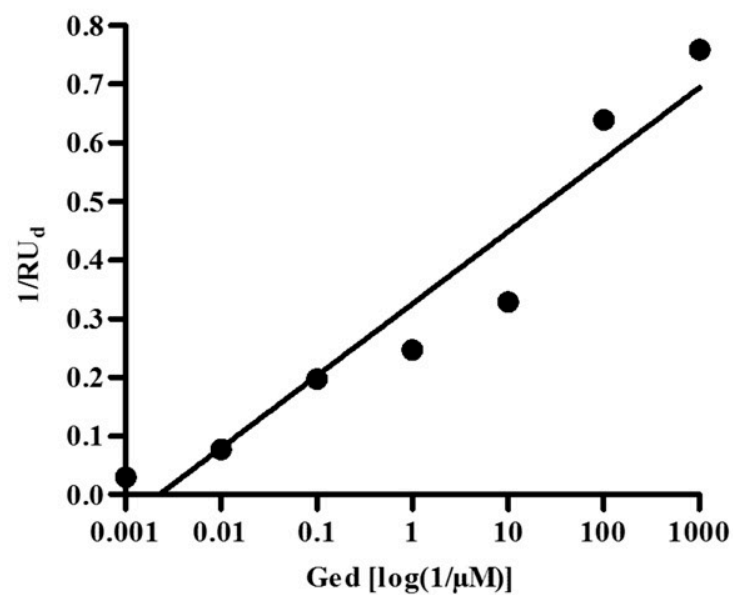

D
0.001

0.01

0.1

1

10

100

1000

Ged

$(\mu \mathrm{M})$

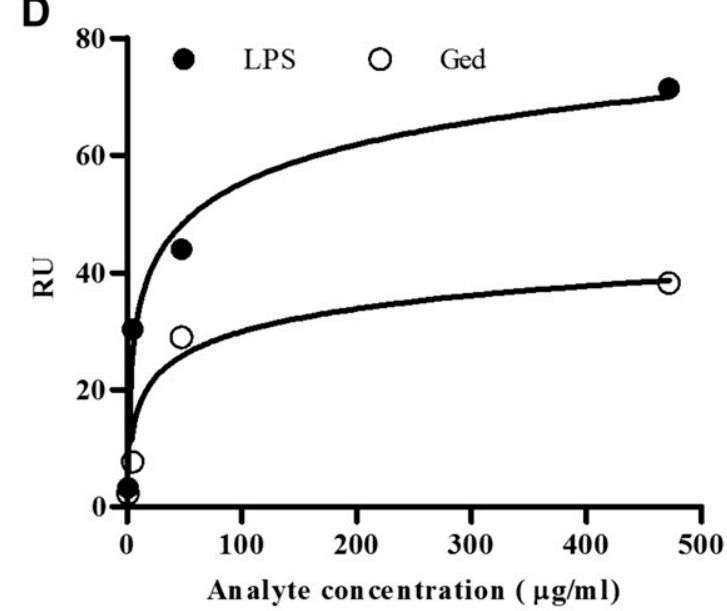

E

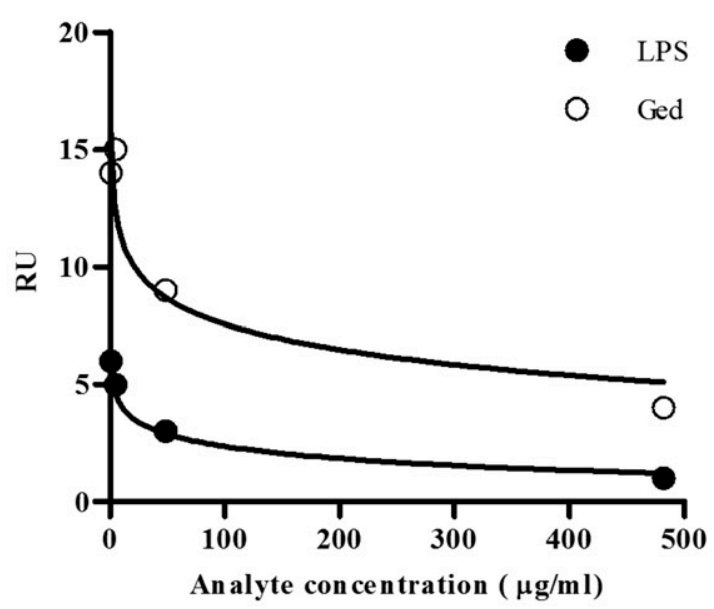

$\mathbf{F}$

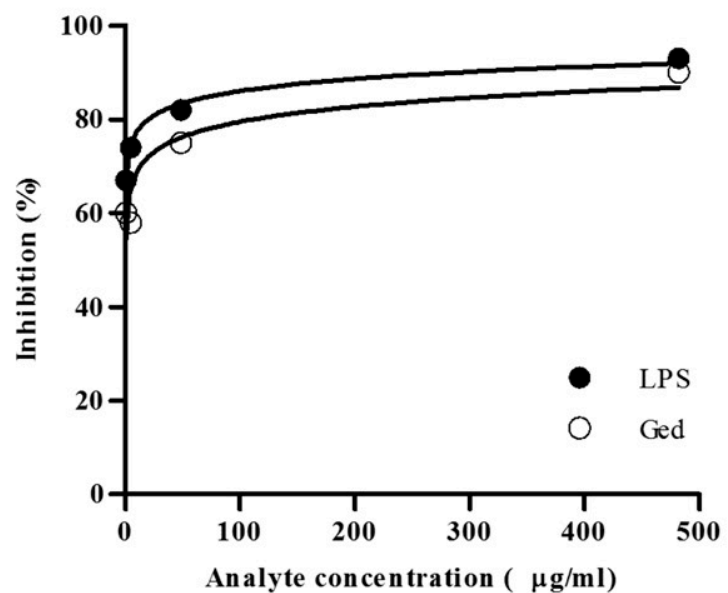

Fig. 7. Biosensing surface assays to assess the binding of gedunin and LPS to immobilized MD-2. After covering the HisCap chip with MD-2, the binding assay of gedunin (Ged; $0.001-1000 \mu \mathrm{M}$ ) was followed by the variation of response throughout 890 seconds. (A and B) Resonance signals are represented by sensorgram in arbitrary RU analyzed after subtraction of a reference line using Qdat software. (C) Double-reciprocal plot linearization of gedunin binding to MD-2. (D) Concentration curves of binding of gedunin and LPS $(0.482-482 \mu \mathrm{g} / \mathrm{ml}$ ) to immobilized MD-2. (E) Binding inhibition curves of gedunin by LPS $\left(R^{2}=0.9883\right)$ and of LPS by gedunin $\left(R^{2}=0.8511\right.$ ), analyzed using $14.5 \mu \mathrm{g} / \mathrm{ml}$ gedunin and $9.64 \mu \mathrm{g} / \mathrm{ml} \mathrm{LPS}$, after 20 seconds of dissociation time. (F) Percentage of binding inhibition. The degree of inhibition was measured considering $100 \%$ as the resonance signal of $1 / \mathrm{RU}_{\max }$ of gedunin $(\mathrm{RU}=19.33)$ and LPS $(\mathrm{RU}=35.00)$. Data are representative of five experiments. 
LPS-triggered response (i.e., blocking the upstream signaling of TLR4/MD-2).

In addition to the ability to inhibit LPS-induced proinflammatory mediators, gedunin also triggered anti-inflammatory factors, namely HO-1 (Hsp32), Hsp70, and IL-10. Supporting our data, the induction of Hsps, including HO-1, by the Hsp90 inhibitor celastrol was previously demonstrated in vitro and in vivo (Trott et al., 2008; Chow et al., 2013; Der Sarkissian et al., 2014). HO-1 is the inducible isoform of the first and ratelimiting enzyme of heme degradation, which is widely expressed during cellular stress and inflammation, triggered by diverse stimuli, including LPS (Camhi et al., 1995, 1998). During inflammation, HO-1 plays roles in anti-inflammatory and immunomodulatory responses, mediated by the degradation of proinflammatory free heme, as well as via the production of bilirubin and carbon monoxide, which present antiinflammatory properties (Gozzelino et al., 2010; Naito et al., 2014). As described in the literature, LPS in vitro stimulation triggers increased HO-1 expression, induced by IL-10, via a p38 MAPK-dependent pathway (Lee and Chau, 2002). In addition, it has been demonstrated that carbon monoxide attenuates Hsp90 activity and promotes dissociation of its client proteins (Lee et al., 2014). Here, we demonstrate that this stressinducible protein was increased by gedunin incubation in the presence or absence of LPS, suggesting that, in our experimental model, gedunin effects are likely a result of both MD-2 binding and Hsp90 modulation. The fact that HO-1 expression was higher in gedunin pretreated macrophages compared with medium- or LPS-stimulated cells reinforces that gedunin can modulate macrophage function independently of TLR4/MD-2 activation, likely via Hsp90.

The inhibition of Hsp90 activity has been shown to induce increased expression of Hsp70 and Hsp90 via HSF-1 activation and is related to cell protection during stress (Sharp et al., 2013; Paul and Mahanta, 2014; Leung et al., 2015). Accordingly, we observed the induction of Hsp90 expression in LPSstimulated macrophages pretreated with gedunin, 17-AAG, and dexamethasone (which also modulates HSF-1 activity; Knowlton and Sun, 2001) (Supplemental Fig. 3). Overexpression or induction of intracellular Hsp70 (by stress or by Hsp70inducing compounds) has been shown to decrease nuclear $\mathrm{NF}_{\kappa} \mathrm{B}$ translocation, inducible nitric oxide synthase expression, and production of TNF- $\alpha$, IL-6, IL- $1 \beta$, and NO (Shi et al., 2006; Dokladny et al., 2010; Kim et al., 2012; Muralidharan et al., 2014). Accordingly, it has been demonstrated that extracellular Hsp70 diminishes LPS-induced TNF- $\alpha$ by bone marrow-derived dendritic cells in vitro and induces IL-10 production by synovial cells from patients with arthritis (Detanico et al., 2004). The anti-inflammatory cytokine IL-10 suppresses LPS-induced macrophage activation by inhibiting the expression of specific TLR-induced proinflammatory genes referred to as "IL-10 counter-regulated genes" (Moore et al., 1993; Cardwall and Weaver, 2014). It is noteworthy that IL-10-mediated anti-inflammatory response is also mediated by HO-1 expression (Lee and Chau, 2002). Interestingly, our study revealed that gedunin acts as an Hsp70 inducer and also increases the production of IL-10, supporting its antiinflammatory and immunomodulatory effects.

Based on the assumptions that p23 and MD-2 share some structural similarity and that gedunin binds to p23, we hypothesized that gedunin might bind to MD-2. Supporting the biologic effects observed with LPS-activated macrophages pretreated with gedunin, our in silico results showed that gedunin docked to the MD-2 large hydrophobic site that overlaps to the LPS binding site, avoiding the formation of the complex between CD14/MD-2/TLR4 and LPS. Furthermore, the binding of gedunin to MD-2 proposed by our docking experiments was proved by the biosensing surface assays we performed. Even though the physicochemical conditions in the SPR assays might not exactly reflect that of the cellular microenvironment, the affinity of gedunin to MD-2 corroborates our in vitro data. The measurement of kinetic values strongly indicates that gedunin is capable of forming complexes with MD-2 and therefore acts as anti-inflammatory in LPS-stimulated macrophages. On the basis of our SPR data, the Gibbs free energy of the formed complexes suggests that gedunin spontaneously binds to MD-2. This finding is physicochemical proof that gedunin interferes with the binding of LPS to MD-2 as a competitive inhibitor and therefore impairs the formation of TLR4/MD-2/LPS complex. Overall, our data suggest that, in addition to Hsp90 modulation, gedunin impairs the TLR4 signaling pathway by inhibiting the binding of LPS to MD-2 in macrophages.

\section{Acknowledgments}

The authors thank Thomas Krahe for critical reading of the manuscript and Thadeu Costa, Leonardo Seito, Tatiana Pádua, and Kennedy Bonjour for technical assistance.

\section{Authorship Contributions}

Participated in research design: Pacheco, Penido.

Conducted experiments: Borges, Moret, Souza-Silva, Batista.

Contributed new reagents or analytic tools: Maya-Monteiro, Alves, Caffarena, Pacheco, Henriques, Penido.

Performed data analysis: Borges, Moret, Maya-Monteiro, Souza-Silva, Batista, Penido.

Wrote or contributed to the writing of the manuscript: Borges, Moret, Alves, Batista, Penido.

\section{References}

Akira S and Takeda K (2004) Toll-like receptor signalling. Nat Rev Immunol 4: 499-511.

Alhouayek M and Muccioli GG (2014) COX-2-derived endocannabinoid metabolites as novel inflammatory mediators. Trends Pharmacol Sci 35:284-292.

Ambade A, Catalano D, Lim A, and Mandrekar P (2012) Inhibition of heat shock protein (molecular weight $90 \mathrm{kDa}$ ) attenuates proinflammatory cytokines and prevents lipopolysaccharide-induced liver injury in mice. Hepatology $\mathbf{5 5}$ $1585-1595$.

Arias-Negrete S, Keller K, and Chadee K (1995) Proinflammatory cytokines regulate cyclooxygenase-2 mRNA expression in human macrophages. Biochem Biophys Res Commun 208:582-589.

Beutler B, Hoebe K, Du X, and Ulevitch RJ (2003) How we detect microbes and respond to them: the Toll-like receptors and their transducers. J Leukoc Biol $\mathbf{7 4}$ $479-485$.

Bode JG, Ehlting C, and Häussinger D (2012) The macrophage response towards LPS and its control through the p38(MAPK)-STAT3 axis. Cell Signal 24:1185-1194.

Bode JG, Schweigart J, Kehrmann J, Ehlting C, Schaper F, Heinrich PC, and Häussinger D (2003) TNF-alpha induces tyrosine phosphorylation and recruitment of the Src homology protein-tyrosine phosphatase 2 to the gp130 signaltransducing subunit of the IL-6 receptor complex. J Immunol 171:257-266.

Brandt GE, Schmidt MD, Prisinzano TE, and Blagg BS (2008) Gedunin, a novel hsp90 inhibitor: semisynthesis of derivatives and preliminary structure-activity relationships. J Med Chem 51:6495-6502.

Byrd CA, Bornmann W, Erdjument-Bromage H, Tempst P, Pavletich N, Rosen N, Nathan CF, and Ding A (1999) Heat shock protein 90 mediates macrophage activation by Taxol and bacterial lipopolysaccharide. Proc Natl Acad Sci USA 96: $5645-5650$.

Byrd-Leifer CA, Block EF, Takeda K, Akira S, and Ding A (2001) The role of MyD88 and TLR4 in the LPS-mimetic activity of Taxol. Eur J Immunol 31:2448-2457.

Camhi SL, Alam J, Otterbein L, Sylvester SL, and Choi AM (1995) Induction of heme oxygenase-1 gene expression by lipopolysaccharide is mediated by AP-1 activation Am J Respir Cell Mol Biol 13:387-398.

Camhi SL, Alam J, Wiegand GW, Chin BY, and Choi AM (1998) Transcriptional activation of the HO-1 gene by lipopolysaccharide is mediated by $5^{\prime}$ distal enhancers: role of reactive oxygen intermediates and AP-1. Am J Respir Cell Mol Biol 18:226-234. 
Cardwall LN and Weaver BK (2014) IL-10 inhibits LPS-induced expression of miR-147 in murine macrophages. Adv Biol Chem 4:261-273.

Chow AM, Tang DW, Hanif A, and Brown IR (2013) Induction of heat shock proteins in cerebral cortical cultures by celastrol. Cell Stress Chaperones 18:155-160.

Conte FP, Ferraris FK, Costa TE, Pacheco P, Seito LN, Verri WA, Jr, Cunha FQ, Penido C, and Henriques MG (2015) Effect of gedunin on acute articular inflammation and hypernociception in mice. Molecules 20:2636-2657.

D'Acquisto F, May MJ, and Ghosh S (2002) Inhibition of nuclear factor kappa B (NF-B): an emerging theme in anti-inflammatory therapies. Mol Interv 2:22-35.

da Silva Correia J, Soldau K, Christen U, Tobias PS, and Ulevitch RJ (2001) Lipopolysaccharide is in close proximity to each of the proteins in its membrane receptor complex. transfer from CD14 to TLR4 and MD-2. J Biol Chem 276:21129-21135.

Davis MA and Carbott DE (1999) Herbimycin A and geldanamycin inhibit okadaic acid-induced apoptosis and p38 activation in NRK-52E renal epithelial cells. Toxicol Appl Pharmacol 161:59-74.

Der Sarkissian S, Cailhier JF, Borie M, Stevens LM, Gaboury L, Mansour S, Hamet $\mathrm{P}$, and Noiseux N (2014) Celastrol protects ischaemic myocardium through a heat shock response with up-regulation of haeme oxygenase-1. $\mathrm{Br} J$ Pharmacol 171: 5265-5279.

Detanico T, Rodrigues L, Sabritto AC, Keisermann M, Bauer ME, Zwickey H, and Bonorino C (2004) Mycobacterial heat shock protein 70 induces interleukin-10 production: immunomodulation of synovial cell cytokine profile and dendritic cell maturation. Clin Exp Immunol 135:336-342.

Dokladny K, Lobb R, Wharton W, Ma TY, and Moseley PL (2010) LPS-induced cytokine levels are repressed by elevated expression of HSP70 in rats: possible role of NF-kappaB. Cell Stress Chaperones 15:153-163.

Dolinsky TJ, Czodrowski P, Li H, Nielsen JE, Jensen JH, Klebe G, and Baker NA (2007) PDB2PQR: expanding and upgrading automated preparation of biomolecular structures for molecular simulations. Nucleic Acids Research 35:W522-W525.

Dolinsky TJ, Nielsen JE, McCammon JA, and Baker NA (2004) PDB2PQR: an automated pipeline for the setup of Poisson-Boltzmann electrostatics calculations. Nucleic Acids Research 32:W665-W667.

Dos Santos CC and Slutsky AS (2000) Invited review: mechanisms of ventilatorinduced lung injury: a perspective. J Appl Physiol (1985) 89:1645-1655.

Echeverría PC, Bernthaler A, Dupuis P, Mayer B, and Picard D (2011) An interaction network predicted from public data as a discovery tool: application to the Hsp90 molecular chaperone machine. PLoS One 6:e26044.

Eisenberg D, Schwarz E, Komaromy M, and Wall R (1984) Analysis of membrane and surface protein sequences with the hydrophobic moment plot. $J$ Mol Biol $\mathbf{1 7 9}$ $125-142$

Eliopoulos AG, Dumitru CD, Wang CC, Cho J, and Tsichlis PN (2002) Induction of COX-2 by LPS in macrophages is regulated by Tpl2-dependent CREB activation signals. EMBO J 21:4831-4840.

Endo Y, Blinova K, Romantseva T, Golding H, and Zaitseva M (2014) Differences in PGE2 production between primary human monocytes and differentiated macrophages: role of IL-1 $\beta$ and TRIF/IRF3. PLoS One 9:e98517.

Ferraris FK, Moret KH, Figueiredo AB, Penido C, and Henriques Md (2012) Gedunin, a natural tetranortriterpenoid, modulates $\mathrm{T}$ lymphocyte responses and ameliorates allergic inflammation. Int Immunopharmacol 14:82-93.

Ferraris FK, Rodrigues R, da Silva VP, Figueiredo R, Penido C, and Henriques Md (2011) Modulation of T lymphocyte and eosinophil functions in vitro by natura tetranortriterpenoids isolated from Carapa guianensis Aublet. Int Immunopharmacol 11:1-11.

Fitzgerald KA, Rowe DC, Barnes BJ, Caffrey DR, Visintin A, Latz E, Monks B, Pitha PM, and Golenbock DT (2003) LPS-TLR4 signaling to IRF-3/7 and NF-kappaB involves the toll adapters TRAM and TRIF. J Exp Med 198:1043-1055.

Gais P, Tiedje C, Altmayr F, Gaestel M, Weighardt H, and Holzmann B (2010) TRIF signaling stimulates translation of TNF-alpha mRNA via prolonged activation of MK2. J Immunol 184:5842-5848.

Gozzelino R, Jeney V, and Soares MP (2010) Mechanisms of cell protection by heme oxygenase-1. Annu Rev Pharmacol Toxicol 50:323-354.

Henriques Md and Penido C (2014) The therapeutic properties of Carapa guianensis. Curr Pharm Des 20:850-856.

Hinz M, Broemer M, Arslan SC, Otto A, Mueller EC, Dettmer R, and Scheidereit C (2007) Signal responsiveness of IkappaB kinases is determined by Cdc37-assisted transient interaction with Hsp90. J Biol Chem 282:32311-32319.

Hirschfeld M, Ma Y, Weis JH, Vogel SN, and Weis JJ (2000) Cutting edge: repurification of lipopolysaccharide eliminates signaling through both human and murine toll-like receptor 2. J Immunol 165:618-622.

Hwang D, Jang BC, Yu G, and Boudreau M (1997) Expression of mitogen-inducible cyclooxygenase induced by lipopolysaccharide: mediation through both mitogenactivated protein kinase and NF-kappaB signaling pathways in macrophages. Biochem Pharmacol 54:87-96.

Kagan JC, Su T, Horng T, Chow A, Akira S, and Medzhitov R (2008) TRAM couples endocytosis of Toll-like receptor 4 to the induction of interferon-beta. Nat Immunol $\mathbf{9}$ 361-368.

Kamath SG, Chen N, Xiong Y, Wenham R, Apte S, Humphrey M, Cragun J, and Lancaster JM (2009) Gedunin, a novel natural substance, inhibits ovarian cancer cell proliferation. Int J Gynecol Cancer 19:1564-1569.

Kawai T and Akira S (2011) Toll-like receptors and their crosstalk with other innate receptors in infection and immunity. Immunity 34:637-650.

Kim N, Kim JY, and Yenari MA (2012) Anti-inflammatory properties and pharmacological induction of Hsp70 after brain injury. Inflammopharmacology 20:177-185.

Knowlton AA and Sun L (2001) Heat-shock factor-1, steroid hormones, and regulation of heat-shock protein expression in the heart. Am J Physiol Heart Circ Physiol 280:H455-H464

Latz E, Visintin A, Lien E, Fitzgerald KA, Monks BG, Kurt-Jones EA, Golenbock DT and Espevik T (2002) Lipopolysaccharide rapidly traffics to and from the Golgi apparatus with the toll-like receptor 4-MD-2-CD14 complex in a process that is distinct from the initiation of signal transduction. J Biol Chem 277:47834-47843.
Lee TS and Chau LY (2002) Heme oxygenase-1 mediates the anti-inflammatory effect of interleukin-10 in mice. Nat Med 8:240-246.

Lee WY, Chen YC, Shih CM, Lin CM, Cheng CH, Chen KC, and Lin CW (2014) The induction of heme oxygenase- 1 suppresses heat shock protein 90 and the proliferation of human breast cancer cells through its byproduct carbon monoxide. Toxicol Appl Pharmacol 274:55-62.

Leung AM, Redlak MJ, and Miller TA (2015) Role of heat shock proteins in oxygen radical-induced gastric apoptosis. J Surg Res 193:135-144.

Lewis J, Devin A, Miller A, Lin Y, Rodriguez Y, Neckers L, and Liu ZG (2000) Disruption of hsp90 function results in degradation of the death domain kinase, receptor-interacting protein (RIP), and blockage of tumor necrosis factor-induced nuclear factor-kappaB activation. $J$ Biol Chem 275:10519-10526.

Li C, Zienkiewicz J, and Hawiger J (2005a) Interactive sites in the MyD88 Toll/ interleukin (IL) 1 receptor domain responsible for coupling to the IL1beta signaling pathway. J Biol Chem 280:26152-26159.

$\mathrm{Li} \mathrm{H}$, Robertson $\mathrm{AD}$, and Jensen $\mathrm{JH}(2005 \mathrm{~b})$ Very fast empirical prediction and rationalization of protein pKa values. Proteins 61:704-721.

Luo S, Wang T, Qin H, Lei H, and Xia Y (2011) Obligatory role of heat shock protein 90 in iNOS induction. Am J Physiol Cell Physiol 301:C227-C233.

Malhotra V, Shanley TP, Pittet JF, Welch WJ, and Wong HR (2001) Geldanamycin inhibits NF-kappaB activation and interleukin-8 gene expression in cultured human respiratory epithelium. Am J Respir Cell Mol Biol 25:92-97.

Marshall JC (2001) Inflammation, coagulopathy, and the pathogenesis of multiple organ dysfunction syndrome. Crit Care Med 29 (Suppl):S99-S106.

Matts RL, Brandt GE, Lu Y, Dixit A, Mollapour M, Wang S, Donnelly AC, Neckers L, Verkhivker G, and Blagg BS (2011) A systematic protocol for the characterization of Hsp90 modulators. Bioorg Med Chem 19:684-692.

McClellan AJ, Xia Y, Deutschbauer AM, Davis RW, Gerstein M, and Frydman J (2007) Diverse cellular functions of the Hsp90 molecular chaperone uncovered using systems approaches. Cell 131:121-135.

Meng J, Lien E, and Golenbock DT (2010) MD-2-mediated ionic interactions between lipid A and TLR4 are essential for receptor activation. J Biol Chem 285: 8695-8702.

Miranda Júnior RN, Dolabela MF, da Silva MN, Póvoa MM, and Maia JG (2012) Antiplasmodial activity of the andiroba (Carapa guianensis Aubl., Meliaceae) oil and its limonoid-rich fraction. J Ethnopharmacol 142:679-683.

Moore KW, O'Garra A, de Waal Malefyt R, Vieira P, and Mosmann TR (1993) Interleukin-10. Annu Rev Immunol 11:165-190.

Muralidharan S, Ambade A, Fulham MA, Deshpande J, Catalano D, and Mandrekar $\mathrm{P}$ (2014) Moderate alcohol induces stress proteins HSF1 and hsp70 and inhibits proinflammatory cytokines resulting in endotoxin tolerance. $J$ Immunol 193 1975-1987.

Naito Y, Takagi T, and Higashimura Y (2014) Heme oxygenase-1 and antiinflammatory M2 macrophages. Arch Biochem Biophys 564:83-88.

Ohto U, Fukase K, Miyake K, and Satow Y (2007) Crystal structures of human MD-2 and its complex with antiendotoxic lipid IVa. Science 316:1632-1634.

Park BS, Song DH, Kim HM, Choi BS, Lee H, and Lee JO (2009) The structural basis of lipopolysaccharide recognition by the TLR4-MD-2 complex. Nature 458 1191-1195.

Pastushok L, Moraes TF, Ellison MJ, and Xiao W (2005) A single Mms2 "key" residue insertion into a Ubc13 pocket determines the interface specificity of a human Lys63 ubiquitin conjugation complex. J Biol Chem 280:17891-17900.

Patwardhan CA, Fauq A, Peterson LB, Miller C, Blagg BS, and Chadli A (2013) Gedunin inactivates the co-chaperone p23 protein causing cancer cell death by apoptosis. J Biol Chem 288:7313-7325.

Paul S and Mahanta S (2014) Association of heat-shock proteins in various neurodegenerative disorders: is it a master key to open the therapeutic door? Mol Cell Biochem 386:45-61.

Penido C, Conte FP, Chagas MS, Rodrigues CA, Pereira JF, and Henriques MG 2006a) Antiinflammatory effects of natural tetranortriterpenoids isolated from Carapa guianensis Aublet on zymosan-induced arthritis in mice. Inflamm Res $\mathbf{5 5}$ : 457-464.

Penido C, Costa KA, Costa MF, Pereira JdeF, Siani AC, and Henriques Md (2006b) Inhibition of allergen-induced eosinophil recruitment by natural tetranortriterpenoids is mediated by the suppression of IL-5, CCL11/eotaxin and NFkappaB activation. Int Immunopharmacol 6:109-121.

Penido C, Costa KA, Pennaforte RJ, Costa MF, Pereira JF, Siani AC, and Henriques MG (2005) Anti-allergic effects of natural tetranortriterpenoids isolated from Carapa guianensis Aublet on allergen-induced vascular permeability and hyperalgesia. Inflamm Res 54:295-303.

Picard D (2002) Heat-shock protein 90, a chaperone for folding and regulation. Cell Mol Life Sci 59:1640-1648.

Poulaki V, Iliaki E, Mitsiades N, Mitsiades CS, Paulus YN, Bula DV, Gragoudas ES, and Miller JW (2007) Inhibition of Hsp90 attenuates inflammation in endotoxininduced uveitis. FASEB $J$ 21:2113-2123.

Pratt WB and Toft DO (1997) Steroid receptor interactions with heat shock protein and immunophilin chaperones. Endocr Rev 18:306-360.

Pritchard KA, Jr, Ackerman AW, Gross ER, Stepp DW, Shi Y, Fontana JT, Baker JE and Sessa WC (2001) Heat shock protein 90 mediates the balance of nitric oxide and superoxide anion from endothelial nitric-oxide synthase. J Biol Chem 276: 17621-17624.

Rhee SH and Hwang D (2000) Murine TOLL-like receptor 4 confers lipopolysaccharide responsiveness as determined by activation of NF kappa B and expression of the inducible cyclooxygenase. J Biol Chem 275:34035-34040.

Richter K and Buchner J (2001) Hsp90: chaperoning signal transduction. J Cell Physiol 188:281-290.

Rushworth SA, Chen XL, Mackman N, Ogborne RM, and O'Connell MA (2005) Lipopolysaccharide-induced heme oxygenase-1 expression in human monocytic cells is mediated via Nrf2 and protein kinase C. J Immunol 175(7): 4408-15. 
Samoylov AV, Mirskya VM, Haoa Q, Swarta C, Shirshovb YM, and Wolfbeisa OS (2005) Nanometer-thick SPR sensor for gaseous HCl. Sens Actuators B Chem 106: 369-372.

Sato S, Sugiyama M, Yamamoto M, Watanabe Y, Kawai T, Takeda K, and Akira S (2003) Toll/IL-1 receptor domain-containing adaptor inducing IFN-beta (TRIF associates with TNF receptor-associated factor 6 and TANK-binding kinase 1, and activates two distinct transcription factors, NF-kappa B and IFN-regulatory factor3 , in the Toll-like receptor signaling. J Immunol 171:4304-4310.

Shamovsky I and Nudler E (2008) New insights into the mechanism of heat shock response activation. Cell Mol Life Sci 65:855-861.

Sharp FR, Zhan X, and Liu DZ (2013) Heat shock proteins in the brain: role of Hsp70, Hsp 27, and HO-1 (Hsp32) and their therapeutic potential. Transl Stroke Res 4:685-692.

Shen FM, Guan YF, Xie HH, and Su DF (2004) Arterial baroreflex function determines the survival time in lipopolysaccharide-induced shock in rats. Shock 21:556-560.

Shi L, Zhang Z, Fang S, Xu J, Liu J, Shen J, Fang F, Luo L, and Yin Z (2009) Heat shock protein 90 (Hsp90) regulates the stability of transforming growth factor betaactivated kinase 1 (TAK1) in interleukin-1beta-induced cell signaling. Mol Immunol 46:541-550.

Shi Y, Tu Z, Tang D, Zhang H, Liu M, Wang K, Calderwood SK, and Xiao X (2006) The inhibition of LPS-induced production of inflammatory cytokines by HSP70 involves inactivation of the NF-kappaB pathway but not the MAPK pathways. Shock 26:277-284.

Shimazu R, Akashi S, Ogata H, Nagai Y, Fukudome K, Miyake K, and Kimoto M (1999) MD-2, a molecule that confers lipopolysaccharide responsiveness on Tolllike receptor 4. J Exp Med 189:1777-1782.

Song Y, Shi Y, Ao LH, Harken AH, and Meng XZ (2003) TLR4 mediates LPS-induced HO-1 expression in mouse liver: role of TNF-alpha and IL-1beta. World J Gas troenterol 9(8):1799-803.

Souza-Silva F, Pereira BA, Finkelstein LC, Zucolotto V, Caffarena ER, and Alves CR (2014) Dynamic identification of $\mathrm{H} 2$ epitopes from Leishmania (Leishmania) amazonensis cysteine proteinase $B$ with potential immune activity during murine infection. J Mol Recognit 27:98-105.

Su GL (2002) Lipopolysaccharides in liver injury: molecular mechanisms of Kupffer cell activation. Am J Physiol Gastrointest Liver Physiol 283:G256-G265.

Triantafilou K, Triantafilou M, Ladha S, Mackie A, Dedrick RL, Fernandez N, and Cherry $R$ (2001) Fluorescence recovery after photobleaching reveals that LPS rapidly transfers from CD14 to hsp70 and hsp90 on the cell membrane. J Cell Sci 114:2535-2545.

Triantafilou M, Morath S, Mackie A, Hartung T, and Triantafilou K (2004) Lateral diffusion of Toll-like receptors reveals that they are transiently confined within lipid rafts on the plasma membrane. J Cell Sci 117:4007-4014.

Triantafilou M, Sawyer D, Nor A, Vakakis E, and Triantafilou K (2008) Cell surface molecular chaperones as endogenous modulators of the innate immune response. Novartis Found Symp 291: 74-79; discussion 79-85, 137-140.

Triantafilou M and Triantafilou K (2004) Heat-shock protein 70 and heat-shock protein 90 associate with Toll-like receptor 4 in response to bacterial lipopolysaccharide. Biochem Soc Trans 32:636-639.
Trott A, West JD, Klaić L, Westerheide SD, Silverman RB, Morimoto RI, and Morano KA (2008) Activation of heat shock and antioxidant responses by the natural product celastrol: transcriptional signatures of a thiol-targeted molecule. Mol Biol Cell 19:1104-1112.

Trott O and Olson AJ (2010) AutoDock Vina: improving the speed and accuracy of docking with a new scoring function, efficient optimization, and multithreading. $J$ Comput Chem 31:455-461.

Ulevitch RJ and Tobias PS (1995) Receptor-dependent mechanisms of cell stimulation by bacterial endotoxin. Annu Rev Immunol 13:437-457.

Vega VL and De Maio A (2003) Geldanamycin treatment ameliorates the response to LPS in murine macrophages by decreasing CD14 surface expression. Mol Biol Cell 14:764-773.

Viriyakosol S, Kirkland T, Soldau K, and Tobias P (2000) MD-2 binds to bacterial lipopolysaccharide. J Endotoxin Res 6:489-491.

Wax S, Piecyk M, Maritim B, and Anderson P (2003) Geldanamycin inhibits the production of inflammatory cytokines in activated macrophages by reducing the stability and translation of cytokine transcripts. Arthritis Rheum 48:541-550.

Weaver AJ, Sullivan WP, Felts SJ, Owen BA, and Toft DO (2000) Crystal structure and activity of human p23, a heat shock protein 90 co-chaperone. J Biol Chem $\mathbf{2 7 5}$ : $23045-23052$.

Wright SD, Ramos RA, Tobias PS, Ulevitch RJ, and Mathison JC (1990) CD14, a receptor for complexes of lipopolysaccharide (LPS) and LPS binding protein. Science 249:1431-1433.

Yamamoto M, Sato S, Hemmi H, Uematsu S, Hoshino K, Kaisho T, Takeuchi O, Takeda $\mathrm{K}$, and Akira S (2003) TRAM is specifically involved in the Toll-like receptor 4-mediated MyD88-independent signaling pathway. Nat Immunol 4:1144-1150.

Yang K, Shi H, Qi R, Sun S, Tang Y, Zhang B, and Wang C (2006) Hsp90 regulates activation of interferon regulatory factor 3 and TBK-1 stabilization in Sendai virusinfected cells. Mol Biol Cell 17:1461-1471.

Yoshida M and Xia Y (2003) Heat shock protein 90 as an endogenous protein enhancer of inducible nitric-oxide synthase. J Biol Chem 278:36953-36958.

Yun TJ, Harning EK, Giza K, Rabah D, Li P, Arndt JW, Luchetti D, Biamonte MA, Shi J, and Lundgren K et al. (2011) EC144, a synthetic inhibitor of heat shock protein 90, blocks innate and adaptive immune responses in models of inflammation and autoimmunity. J Immunol 186:563-575.

Zhao R and Houry WA (2005) Hsp90: a chaperone for protein folding and gene regulation. Biochem Cell Biol 83:703-710.

Zimmer SM, Liu J, Clayton JL, Stephens DS, and Snyder JP (2008) Paclitaxel binding to human and murine MD-2. J Biol Chem 283:27916-27926.

Address correspondence to: Dr. Carmen Penido, Laboratory of Applied Pharmacology, Institute of Drug Technology, Oswaldo Cruz Foundation, Rua Sizenando Nabuco, 100, Manguinhos, 21041-250 Rio de Janeiro, RJ, Brazil. E-mail: cpenido@cdts.fiocruz.br 